\title{
التحكيم في عقود نقل التكنولوجيا
}

دراسة مقارنة بين القانون السعودي والقانون المصري

إعداد: د. خالد عبد القادر مهمود عيد

أستاذ مشارك قانوز تجاري

جامعة الطائف

المملكة العربية السعودية
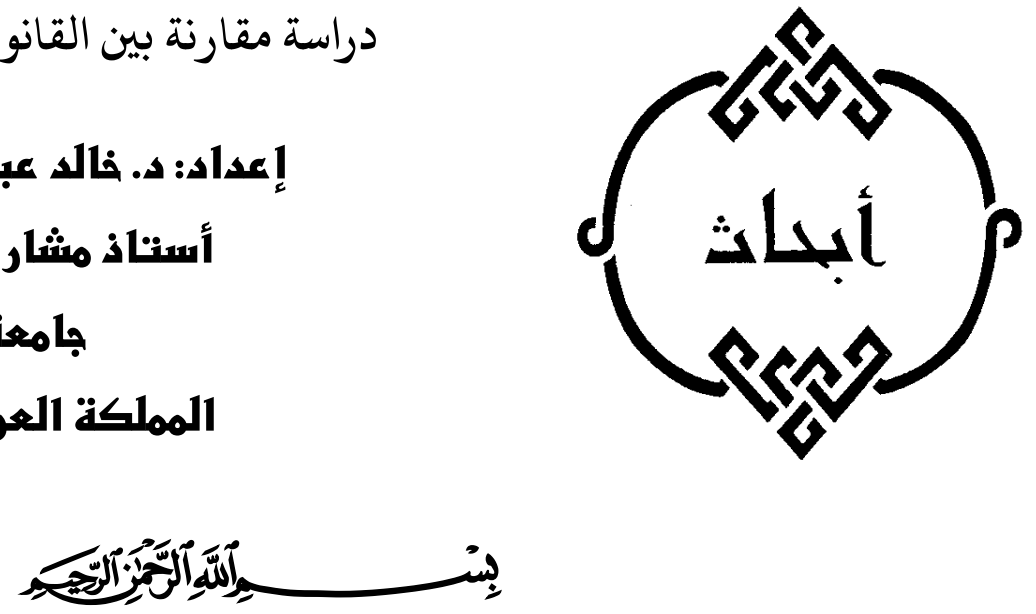

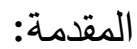

يتمتع عقد نقل التكنولوجيا بخصوصية ينفرد بها، وليست هذه الخصوصية بسبب أنه من العقود التجارية التي تتميز وتختلف عن غيرها من العقود سواء الددنية

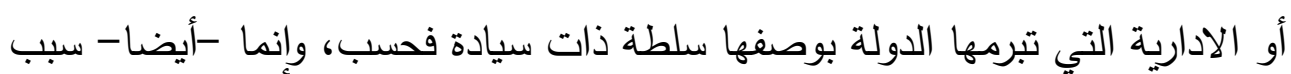
هذه الخصوصية أن عقود نقل التكنولوجيا تعكس العلاقات والفوارق بين الدول.

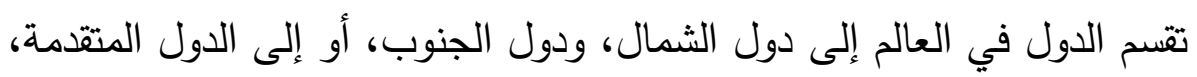

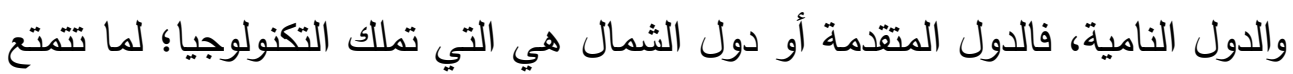

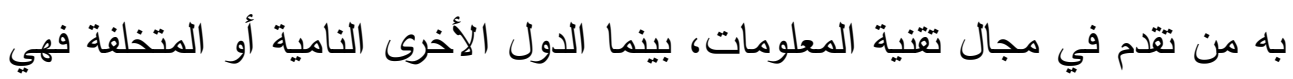

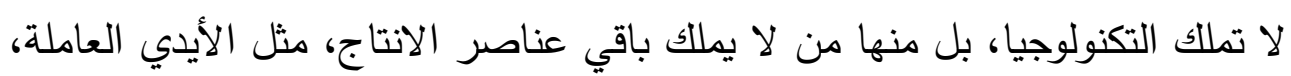
والموارد الطبيعية، اللازمة للإنتاج.

ورغبة من الدول النامية في اللاحاق بركب التقدم الاقتصادي والعلمي التي التي التاني

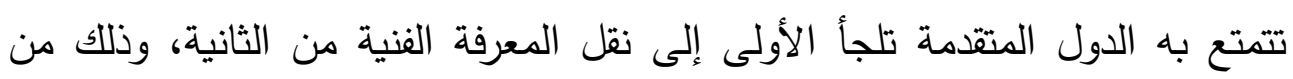

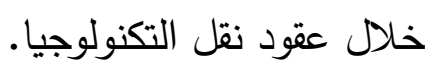


وبذللك يظهر سبب تمييز عقد نقل التكنولوجيا وخصوصيته عن باقي العقود، حيث يعد أداة تستخدمها الدولة في تنفيذ خططها الاقتصادية للنهوض بالاقتصاد الوطني، ومحاولة الخروج من حالة التخلف الاقتصادي. إلا أن الأمر لم يجر على هذا النحو من الوضوح والبساطة بين الدول، حيث تسعى الدول المتقدمة سعيا دائبا إلى الحفاظ علي وجود علاقة تبعية بينها وبين الدول النامبة، بحيث تجعل الآخيرة تابعه إليها دائما وهذا نوع من الاستعمار الاقتصادي الحديث، وتحقق الدول المتقدمة هذا الهدف من خلال السرية التي تعد من أهم عناصر عقود نقل التكنولوجيا، هذه العناصر التي يغلب عليها الطابع المعنوى. والطابع المعنوي الذي يغلب على عقود نقل التكنولوجيا يعد السبب الثاني في تميز هذا النوع من العقود وخصوصيته عن غيرها، حيث غالبا ما تتصب عقود نقل التكنولوجيا على نقل معلومات، أو مساعدة فنية، أو حقوق اختراع، وهذه العناصر المعنوية هي المعيار الجوهري في التمييز بين عقد نقل التكنولوجيا وغيره من العقود، مثل عقد نقل البضائع، أو عقد المقاولة. والنتيجة الأساسية المترتبة علي تمييز عقد نقل التكنولوجيا وخصوصيته أن حظاه المشرع في كثير من البلدان بتظيم قانوني خاص به دون بقية العقود، من ذلك أن المشرع المصري نظم عقود نقل التكنولوجيا في فصل مستقل، هو الفصل الأول من الباب الثاني من قانون التجارة رقم V لسنة 999 ا في المواد من Y V حتى AV. وحيث إن عقود نقل التكنولوجيا مثلها مثل باقي العقود من المتصور أن ينتج عن تنفيذها خلافات ومنازعات بين أطرافها كان لابد من تتظيم كيفية تسوية هذه الخلافات والمناوعات، سواء قضائيا، أم رضائيا، وبالكيفية التي تتفق مع خصوصية عقد نقل التكنولوجيا وطبيعته.

وإن كانت عقود نقل التكنولوجيا جاءت منبثقة عن التطور الهائل في العلاقات الاقتصادية فان هذا التطور ذاته قد أنتج لنا طرقا غير تقليدية لحل المنازعات التي تتشأ عن هذه العلاقات المتشابكة والمترابطة. 
ومن أهم الطرق لحل المناعات الناتجة عن تطور العلاقات الاقتصادية هو

نظام التحكيم الذي بات من نظم حل المنازعات التي لاغنى عنها؛ لما يحققه من تفادٍ

لمساوئ القضاء العادي، لاسيما التأخير في الحكم أحيانا.

خطة البحث: مبن

المقدمة.

المبحث الأول: ماهية عقد نقل التكنولوجيا.

المطلب الأول: تعريف عقد نقل التكنولوجيا.

المطلب الثاني: آثار عقد نقل التكنولوجيا.

المبحث الثاني: ضوابط الاتفاق علي التحكيم في عقد نقل التكنولوجيا.

المطلب الأول: شروط اتفاق التحكيم في عقد نقل التكنولوجيا.

المطلب الثاني: آثار اتفاق التحكيم في عقد نقل التكنولوجيا.

الفرع الأول: الآثار بالنسبة للأطراف.

الفرع الثاني: الآثار بالنسبة للمحكم.

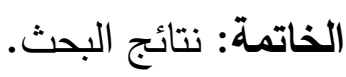

فهرس المصادر والمراجع. 


\section{المبحث الأول}

\section{انعقاد عقد نقل التكنولوجيا}

نتناول هذا المبحث في حدود ضيقة، مقيدين في ذلك بموضوع البحث ككل، وهو التحكيم في عقود نقل التكنولوجيا، ففي هذا المبحث نلقي الضوء علي نقطتين دون تزيد أو تشعب: الأولى: تعريف عقد نقل التكنولوجيا، الثانية: آثار عقد نقل التكنولوجيا.

\section{المطلب الأول}

\section{تعريف عقد نقل التكنولوجيا}

إن عقد نقل التكنولوجيا من العقود المستحدثة التي شاع إبرامها بين الدول المتقدمة والدول النامية، لذلك تعرف بنقل المعرفة الفنية من دول متقدمة إلى دول نامية؛ تحقيقا للتنمية الاقتصادية، وجلبا للاستثمارات الأجنبية. ولم يفرد لها المشرع السعودي تنظيما خاصا على خلاف المشرع المصري، فقد تناول هذا النوع من العقود بالتنظيم في قانون التجارة رقم V V لسنة 999 (1) وعرف عقد نقل التكنولوجيا في المادة VT بأنه "عقد نقل التكنولوجيا اتفاق يتعهد بمقتضاه مورد التكنولوجيا بأن ينقل بمقابل معلومات فنية إلى مستورد التكنولوجيا؛ لاستخدامها

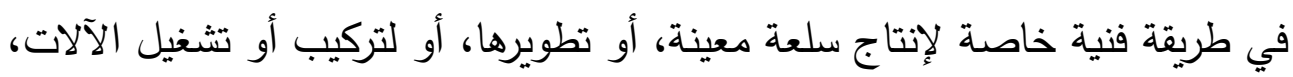
أو أجهزة، أو لتقديم خدمات، ولا يعتبر نقلا لتكنولوجيا مجرد بيع، أو شراء، أو تأجير،

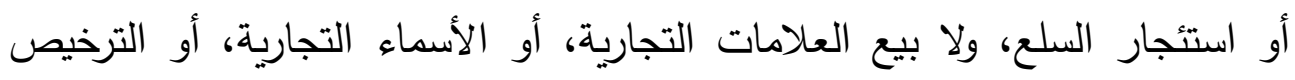
باستعمالها إلا إذا ورد ذلك كجزء من عقد نقل تكنولوجيا، أو كان مرتبطا به".

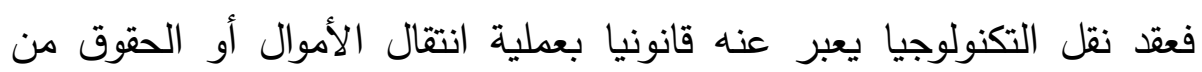
أشخاص قانونية، سواء أكانت أثخاص قانون خاص أفرادا وأشخاصا عتباريةأ أم أشخاص قانون عام الدولة، والهيئات العامة، والوزارات؛ لذلك فهو ينطوي على النقل الكلي، أو الجزئي، النهائي أو المؤقت، للانتقال الفعلي بالأموال، أو الحقوق، أو لون

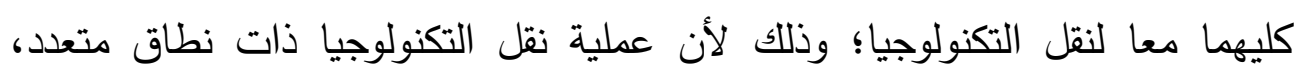
فتوجد تكنولوجيا سرية، وغير سرية، وتكنولوجيا عامة، وأخري خاصة. 
لكن علي أية حال وبعيدا عن أزمة المصطلح ووضع التعريف المنضبط فإن عقد نقل التكنولوجيا يعد اتفاقا ملزما للجانبين، وما يتبع ذلك من أنه في حالة بطلان التزام أحد الطرفين يترتب عليه بطلان العقد'(') وأيضا شاع عند بعض الفقه القانوني أن عقود نقل التكنولوجيا هي مال منقول ذو صفة معنوية، وله قيمة اقتصادية، وغير مشمول بحماية قانونية خاصة، وقد اصطلح على تسميته بحق المعرفة الفنية التي تشكل اليوم أهم عناصر الأصول التكنولوجية للمشروعات الكبرى، وهي المحور

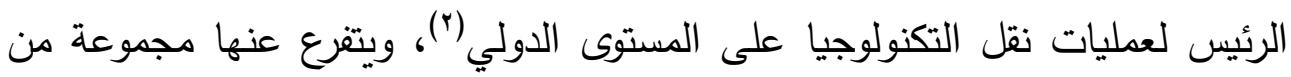
العقود، كعقود التراخيص، وعقود تسليم المفتاح في اليد، وعقود الامتياز كآليات قانونية لهذا النقل.

وعموما فإن عقود نقل التكنولوجيا يتم إبرامها بين الدول النامية والدول المتقدمة،(ז)، أو قد تبرم بين الدولة وأحدى المؤسسات التابعة لها، كما تبرم بين الدولة وإحدى الشركات الأجنبية، مما يعني أن عقود نقل التكنولوجيا عبارة عن مشاريع اقتصادية بين دول تحمل جنسيات مختلفة للنهوض بالقطاع الاقتصادي للدول النامية على وجه الخصوص؛ تحقيقا للتنمية، الثيء الذي يجعل النزاعات في هذا العقد طويل المدى واردة لا محالة؛ لذلك يلجأ أطراف النزاع إلى محكمين للفصل فيما يثور بينهم من نزاعات، بحكم أن مسطرة التحكيم سريعة، وذات تكلفة أقل في حل النزاع، كما تلعب الإرادة دورا مهما في اختيار المحكمين، واختيار القانون الواجب التطبيق.

( (1) مراد محمود المواجده - المسئولية المدنية في عقود نقل التكنولوجيا - ط • ( + - - دار التقافة

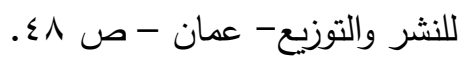
(r) آمال زيدان عبد اللاه، الحماية القانونية للأسرار التجارية في عقود نقل التكنولوجيا: دراسة

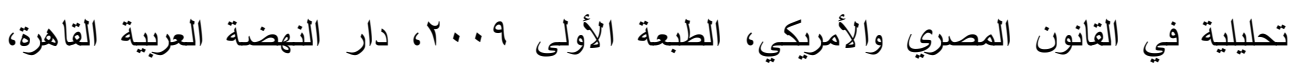

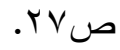
(r) مراد محمود المواجده - المسئولية المدنية في عقود نقل التكنولوجيا - طبعة • (. ب، دار الثقافة للنشر والتوزيع - عمان. 
وقد لاقت عقود نقل التكنولوجيا اهتماما اقتصاديا وسياسيا، لكنها لم تحظ بتنظيم تشريعي إلا من عدد محدود من بعض الدول، كالمشرع المصري، كما لا ينفي أنه لهاب تترتب عنها مجموعة من النصوص القانونية المتعلقة بالملكية الصناعية وفق إجراءات وقواعد محدودة لا تمثلها بأكملها، كما هو الثأن بالقانون السعودي. وبذلك لا يخلو أي عقد من عقود نقل التكنولوجيا من نص يتضمن اتفاق

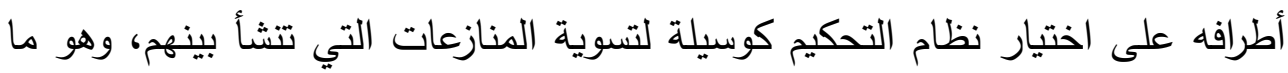
يستدعي اللجوء إلى هذه الآلية عوض القضاء باعتباره من الوسائل القانونية البديلة القائمة على تسهيل الإجراءات، وإيجاد حلول مرضية للأطراف لحل الخلاف بينهم، لذلك يعتبر التحكيم في مثل هذه العقود عملية اختيارية، تتم وفق إرادة الأطراف، يوكل فيها حل النزاع إلى طرف ثالث محايد، يسمى المحكم، يتم اختياره من قبل الأطراف مباشرة، أو بواسطة جهة أخرى يوكل الأطراف إليها هذه المهمة، ليقوم بحل النزاع الناشئ بينهم بحكم ملزم لهم.

شروط عقود نقل التكنولوجيا والأحكام القانونية بثانها: صور التعاقد المرتبطة بترخيص استخدام الملكية الفكرية ونقل التكنولوجيا تثير صعوبات مختلفة، لا بسبب النقص التشريعي - غالبا، وإنما بسبب الثروط الجائرة ومدى تواؤمها مع النظام القانوني للدولة، وما يترتب علي ذلك من ظهور العديد من المنازعات.

ولعل من أهم الشروط التعاقدية في عقود نقل التكنولوجيا هي الثروط المتعلقة بحرية المنافسة المشروعة، بحيث يصبح العقد في ذاته تقييدا للمنافسة المشروعة، وتكريسا لأنماط من الممارسات غير المشروعة('). والإحاطة بهذا البعد وبآلية إبرام الرخص والتفاوض بشأنها يتطلب الوقوف على الشروط العقدية، والتنبه لكل منها، وتصنيفها ضمن مجموعات يسهل التعامل معها.

(1) أحمد عبد الكريم سلامة - شروط الثبات التشريعي في عقود الاستثمار والتجارة الدولية -

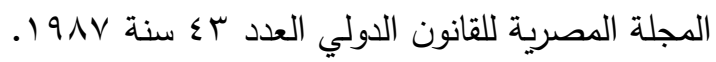
$-11 Y$. 
وعلي أية حال فإن الشروط العقدية لن تخرج عن واحدة من مجموعات ثلاث: الأولى: الشروط العادلة، والثانية: الشروط الجائرة، والثالثة: الشروط التي تتوسط بين الحالتين.

وفي هذا الشأن سوف نجري مقارنة بين كل من المنظم الأردني والمنظم المصري حيث إن كلا منهما أورد تتظيم تشريعي لعقود نقل التكنولوجيا، فقد نظمها المنظم المصري في باب مستقل في قانون التجارة الجدية V ل لسنة 999 19، على حين نظمها المنظم الأردني في قانون المنافسة غير المشروعة.

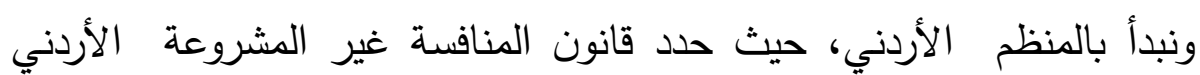
للشروط التي من شانها تقييد المنافسة قرر مبدأ عاما في صدر المادة (في الفقرة أ من

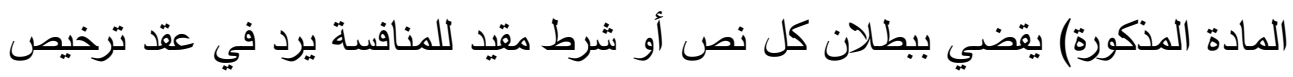
يتعلق بأي من حقوق الملكية الفكرية قد يكون له أثر سلبي على التجارة، وقد يعيق نقل التكنولوجيا ونشرها، ويلاحظ على صياغة المعيار أنه قد نقل حرفيا ما هو مقرر في المادة •ـ من اتفاقية تربس السابق إيراد نصها، وفي الوقت الذي أجازت المادة اتخاذ تدابير لمنع مثل هذه الشروط اختار المشرع جزاء البطلان لها، ولم ينص سوى على ثلاث شروط محددة تعتبر باطلة وفق هذا النص، وهي الشروط العقدية ذاتها التي ورد النص عليها في اتفاقية تربس كاملة، فلم يضف القانون أي شرط آخر ، وهذه الشروط الثلاثة هي: - الثي:

ا- إلزام المرخص له بعدم نقل التحسينات التي يجريها على التكنولوجيا التي يشملها عقد الترخيص إلا للمرخص (النقل العكسي للتكنولوجيا المحسنة). r- منع المرخص له من المنازعة إداريا أو قضائيا في حق الملكية الفكرية الذي تم ترخيصه. - ت

r- إلزام المرخص له بقبول الترخيص بمجموعة من الحقوق بدلا من حق واحد. وبعقد المقارنة مع المنظم المصري في هذا الثان نجد ما يلي: 
نظم المشرع الأردني هذا الموضوع في مادة واحدة من فقرتين نصت على حكم المادة •.ء فقط من اتفاقية تربس، وأضافت فقرة تعريفية بمفهوم حقوق الملكية الفكرية،

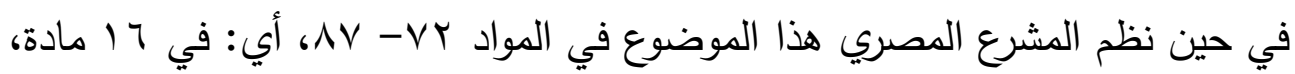
وهو ما يشير التساؤل حول ما جرى تتظيمه تشريعا، وما لم يتم التعرض له. إن شمولية التظيم لم تنشأ عن رغبة في مجرد صياغة الأحكام، بل استتدت الى واقع مرير من المعاناة العربية ومعاناة الدول النامية في منازعاتها مع الدول مصدرة التكنولوجيا، ولهذا جاء التظظيم المصري لهذا الموضوع يعكس المسائل التي تثار في التطبيق العملي، فنظم المشرع المصري نطاق سريان أحكام نقل التكنولوجيا من حيث الأشخاص والعقود، وحدد المقصود بعقد نقل التكنولوجيا، ثم قرر وجوب أن لن يكون مكتوبا تحت طائلة البطلان، ووجوب أن يشتمل العقد على عناصر المعرفة وتوابعها التي تتقل إلى مستورد التكنولوجيا، واعتبر دراسات الجدوى، والتعليمات والتصميمات، والرسومات الهندسية، والخرائط، والصور، وبرامج الحاسب الآلي، وغيرها من الوثائق الموضحة للمعرفة الملحقة بالعقد - جزءا منه، ثم حدد القانون الشروط الجائز إبطالها، وتشمل سبعة شروط عامة، ثم نظم التزامات مورد التكنولوجيا والتزامات متلقي التكنولوجيا، ومسائل اختصاص القانون المصري بنظر منازعات هذه الاتفاقيات.

اعتمد المنظم المصري في تحديده للشروط الجائز إبطالها معيار (الشرط الذي يكون من شأنه تقييد حرية المستورد في الإفادة من التكنولوجيا)، وهو معيار واسع يخدم متلقي التقنية، وفي معرض بيان المشرع للشروط الجائز إبطالها يمكن حصرها فيما يلي: 1- قبول التحسينات التي يدخلها المورد على التكنولوجيا وأداء قيمتها. ץ- حظر إدخال تحسينات أو تعديلات على التكنولوجيا لتلائم الظروف المحلية، أو ظروف منشأة المستورد، وكذلك حظر الحصول على تكنولوجيا أخرى مماثلة أو منافسة للتكنولوجيا محل العقد. 
r- استعمال علامات تجارية معينة لتمييز السلع التي استخدت التكنولوجيا في

إنتاجها.

ع - ت تقيد حجم الإنتاج، أو ثمنه، أو كيفية توزيعه، أو تصديره.

0- اشتراك المورد في إدارة منشأة المستورد، أو تدخله في اختيار العاملين الدائمين

بوان

צ- شراء المواد الخام، أو المعدات، أو الآلات، أو الأجهزة، أو قطع الغيار؛ لتشغيل

التكنولوجيا من المورد وحده، أو من المنشآت التي يعينها دون غيرها.

- V - Vر بيع الإنتاج أو التوكيل في بيعه على المورد أو الاشخاص الذين يعينهم. كما يلاحظ أن الشروط السبعة القابلة للإبطال في القانون المصري غير لإنه الثروط الثلاثة المنصوص عليها في القانون الأردني وفي اتفاقية تربس، بمعنى أننا في هذا الحصر المحدود فقط وجدنا أن ثمة عشرة شروط تعد من قبيل الثروط الجائرة، أو على الأقل يمكن أن تكون كذلك في أحوال معينة، وهي -قطعا- كذلك

فيما يتجاوز نصفها.

وبالتالي نصل إلى نتيجة أن المشرع الأردني لم يول هذا الموضوع الاهتمام

الذي يستحق، واكتفى بتضمين القانون نص الاتفاقية التي هي في حقيقتها جزء من نظامنا القانوني، وتضمينها من عدمه لا ينفي حجيتها، لكن الأكيد أن القانون لم يتضمن ما هو أهم مما ورد في الاتفاقية، الأحكام التفصيلية التي أجازت الاتفاقية نفسها للأردن أن يتخذ التدابير بشانها، ويكرس هذا المسلك، وللأسف اكتفاء جهات إعداد القوانين بما يسلم للأردن أو يطلب منه دون الإفادة مما يسمح له به به عبر الاتفاقيات الخطرة التي بطبيعتها تقيد حقوق الأردن وترتب عليه الالتزامات أكثر مما

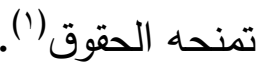

(1) آمال زيدان عبد اللاه - الحماية القانونية للأسرار التجارية في عقود نقل التكنولوجيا: دراسة تحليلية - الطبعه الأولى 9 ... - دار النهضة العربية. $-110$ 


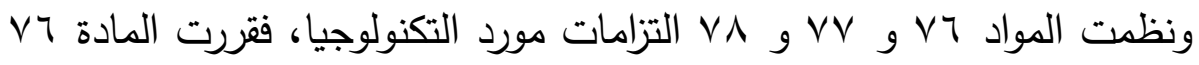
أنه يلتزم بأن يكثف للمستورد في العقد أو خلال المفاوضات التي تسبق إبرامه عن الأخطار التي تتشأ عن استخدام التكنولوجيا، وعلى وجه الخصوص لهان ما يتعلق منها

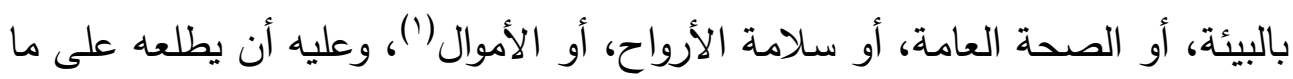

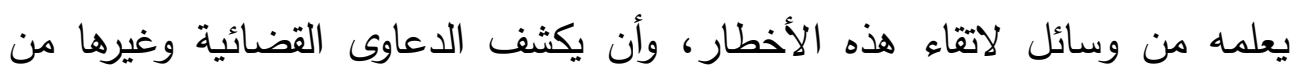
العقبات التي قد تعوق استخدام الحقوق المتصلة بالتكنولوجيا، لا سيما ما يتعلق منها ببراءات الاختراع، وأن يكثف ويضدن العقد أحكام القانون المحلي بشأن التصريح بتصدير التكنولوحيا. ومرد ذلك ما ظهر عمليا في كثير من الحالات من إخلال بالتزام نقل التكنولوجيا تحت ذريعة التعارض مع القانون الوطني، أو بسبب النزاعات القضائية والتذرع بها كظروف طارئة، وما ظهر أيضا في حالات كثيرة من نقل تكنولوجيا بقدر ما يعتقد أنها مفيدة تظهر آثارها المدمرة على البيئة، والإنسان، والصحة، بحيث أصبحت الدول النامية مرتعا للتالف وغير المقبول من تكنولوجيات الغرب. كما قررت المادة VV التزام مورد التكنولوجيا بأن يقدم للمستورد المعلومات والبيانات وغيرها من الوثائق الفنية اللازمة لاستيعاب التكنولوجيا، وكذلك ما يطلبه المستورد من الخدمات الفنية اللازمة لتشغيل التكنولوجيا، وعلى وجه الخصوص لته الخبرة والتدريب، وأن يعلم المستورد بالتحسينات التي قد يدخلها على التكنولوجيا خلال مدة سريان العقد، وأن ينقل هذه التحسينات إلى المستورد إذا طلب منه ذلك. وهذا الحكم يعكس أكبر وأهم مشكلة تواجه الدول النامية في نقل المعرفة والتكنولوجيا، وترخيص الملكية الفكرية تحديدا على برامج الكمبيوتر، حيث تنقل

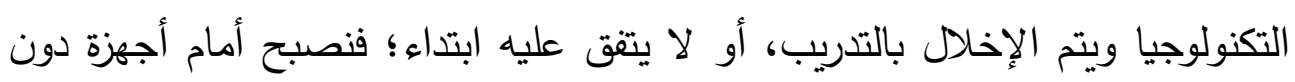
فائدة، أو تنقل دون التزام بالتحسين؛ فيسبق العصر ما جرى استيراده، ويصبح باليا

(1) مراد محمود المواجده - المسئولية المدنية في عقود نقل التكنولوجيا - طبعة • (ب، دار الثقافة للنشر والتوزيع - عمان. 
في مواجهة التقدم السريع الحاصل، وخطورة عدم نقل التحسين والتطوير أن ما استورد يصبح غير متوافق مع ما يكمله من منتجات حديثة. وأما المادة VA فإنها تلزم المورد- طوال مدة سريان العقد - بأن يقدم للمستورد بناء على طلبه قطع الغيار التي ينتجها وتحتاجها الآلات أو الأجهزة التي تستعمل في بان تشغيل منشأته، واذا كان المورد لا ينتج هذه القطع في منشأته وجب أن يعلم المستورد بمصادر الحصول عليها.

وهذه أيضا من المسائل التي أدت في حالات كثيرة إلى خسارة الدول النامية مشروعات ضخمة؛ إذ تتوفر الماكينات والمعدات وتختفي من الأسواق ومن بلد المورد قطع غيارها؛ فتصبح مجرد كتل حديدية لا قيمة لها، ومثل هذه النصوص لم يرد ذكر لها في القانون الأردني من قريب أو بعيد.

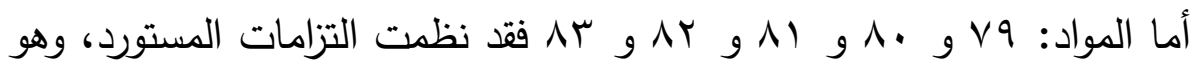
تتظيم ذكي أريد منه إحداث التوازن، وتعريف المورد أن القانون يكفل له حقوقا تشجعه على توريد التكنولوجيا، وبالوقت نفسه تضمن التزام المستورد بمراعاة نظامه القانوني، والتزامته تجاه بلده، وتحديدا في حقول العمالة؛ منعا من تغول أصحاب الثروة على لهى أوطانهم، وعدم مراعاة التزاماتهم تجاه بلدهم.

فتقرر المادة Vq التزام المستورد بأن يستخدم في تشغيل التكنولوجيا عاملين على قدر من الدراية الفنية، وأن يستعين -كلما لزم الأمر - بخبراء فنيين، على أن فئن فئن يكون اختيار هؤلاء العاملين أو الخبراء من المصريين المقيمين في مصر ، أو في لئين الخارج كلما كان ذلك متاحا.

وتقرر المادة • 1 التزام المستورد بأن يطلع المورد على أحكام التشريعات الوطنية المتعلقة باستيراد التكنولوجيا. 
وتقرر المادة 1 1 حظر النزول للغير عن التكنولوجيا التي حصل عليها

المستورد إلا بموافقة موردها(').

كما تقرر المادة r ب التزام المستورد بدفع مقابل التكنولوجيا والتحسينات التي تدخل عليها في الميعاد والمكان المتفق عليهمان وتجيز أن يكون المقابل مبلغا إجماليا يؤدي دفعة واحدة أو على دفعات متعددة، كما يجوز أن يكون المقابل نصيبا من رأس المال المستثمر في تشغيل التكنولوجيا، أو نصيبا من عائد هذا التشغيل، وتجيز أن يكون المقابل كمية معينة من السلعة التي تستخدم التكنولوجيا في إنتاجها أو مادة أولية ينتجها المستورد، ويتعهد بتصديرها إلى المورد.

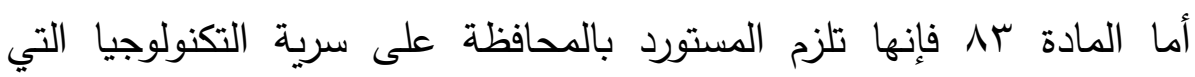
يحصل عليها، وعلى سرية التحسينات التي تدخل عليها، ويسأل عن تعويض الضرر الذي ينشأ عن إفثاء هذه السرية، سواء وقع في مرحلة التفاوض على إبرام العقد أم بعد ذلك، وتلزمه كذلك بالمحافظة على سرية التحسينات التي يدخلها المستورد وينقلها إليه بموجب شرط في العقد، ويسأل المورد عن تعويض الضرر الذي ينشأ عن إفشاء هذه السريـة.

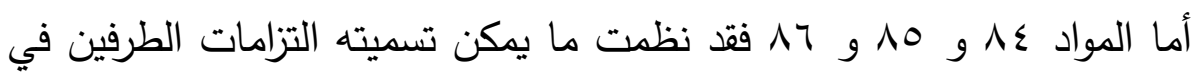
مواجهة الغير، واتفاقات جائزة في هذا النطاق، فالمادة ع^ أجازت الاتفاق على أن يكون لمستورد التكنولوجيا وحده حق استخدامها والاتجار في الإنتاج، وبشرط أن يحدد هذا الحق بمنطقة جغرافية معينة، وبمدة محددة يتفق عليها الطرفان. أما المادة 10 فقد قررت على المورد ضمان مطابقة التكنولوجيا والوثائق المرفقة بها للشروط المبينة في العقد، كما يضدن إنتاج السلعة، أو اداء الخدمات التي اتفق عليها بالمواصفات المبينة في العقد، ما لم يتفق كتابة على خلاف ذلك.

(1) جلال وفاء محمدين - الإطار القانوني لنقل التكنولوجيا - طبعة 1... - دار الجامعة الجديدة للنشر ، الإسكندرية. 
وقررت أيضا أن كلا من المورد والمستورد يسألان بغير تضامن بينهما عما يلحق الأشخاص والأموال من ضرر ناشئ عن استخدام التكنولوجيا، أو عن السلعة لهن الناتجة عن تطبيقها.

وأما المادة ؟1 فإنها أجازت لكل من طرفي عقد نقل التكنولوجيا بعد انقضاء خمس سنوات من تاريخ العقد أن يطلب إنهاءه، أو إعادة النظر في شروطه بتعديلها بما يلائم الظروف الاقتصادية العامة القائمة، ويجوز تكرار تقديم هذا الطلب كلما انقضت خمس سنوات، ما لم يتفق على مدة أخرى. هذه هي مناطق الاهتمام بشأن الأحكام العقدية التي من شأنها أن تقيم توازنا صحيحا ما بين حقوق المورد والمستورد والتزاماتهما في عقود نقل التكنولوجيا، والتراخيص العقدية المتعلقة بالمليكة الفكرية. ويمككنا القول في الختام إن هذه العقود التي تمتد في حالة تراخيص الملكية الفكرية إلى العقود والاتفاقيات المتعلقة بكافة موضوعات الملكية الفكرية على نحو ما تقرره الفقرة ب من المادة 9 من قانون المنافسة غير المشروعة والأسرار التجارية الأردني(') أي تمتد إلى حقوق المؤلف، والحقوق المجاورة لها، والعلامات التجارية، والمؤشرات التجارية، والرسوم الصناعية، والنماذج الصناعية، وبراءات الاختراع، والتصاميم للدوائر المتكاملة، والأسرار التجارية، والأصناف النباتية الجديدة(؟)- نقول: إن هذه العقود تنطوي على أهمية استثنائية في عصر تزداد فيه قيمة الموجودات المعنوية، وتشكل عناصر هامة ومتعاظمة في رأس مال المشروعات، ومحددا إستراتيجيا في نجاح سياسات تطوير الاقتصاد وتتمية المجتمع، ولهذا تستحق تنظيما تشريعا يلاءم مع أهميتها، وهو تتظيم يستفيد مما منحته المادة •ـ من اتفاقية تربس

(1) مراد محمود المواجدة - المسئولية المدنية في عقود نقل التكنولوجيا - ط • ( • ب، دار الثقافة للنشر والتوزيع - عمان.

(r) محمد بن عبد المحسن بن ناصر العبيكان - عقد نقل التكنولوجيا - بحث تكميلي لنيل درجة الماجستير - جامعة الإمام محمد بن سعود الإسلامية. 
للدول الأعضاء من حرية الحركة في حظر أية معوقات، أو ممارسات، أو شروط

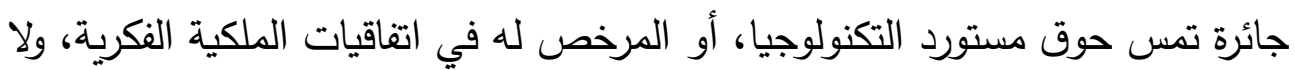
نبالغ إن قلنا إن الكثير من مصانع الدواء -وفي الوقت الراهن - وقعت فريسة اتفاقيات

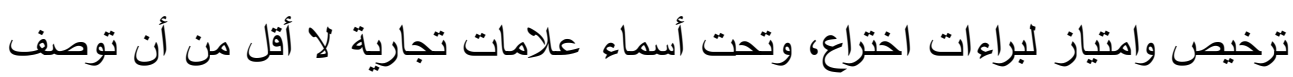
بأنها مدمرة، وستترك أثرا سلبيا على واحدة من أهم صناعاتتا الوطنية. المطلب الثاني

\section{آثار عقد نقل التكنولوجيا}

لا تقف آثار عقد نقل التكنولوجيا على أطرافه فقط، بل من المحتمل أن تمتد هذه الآثار إلى الغير، والمقصود بالغير كل من ليس طرفا في العقد، لذلك سوف نلقي الضوء علي آثار عقد نقل التكنولوجيا، سواء أكانت بالنسبة لأطراف،ه أم كانت بالنسبة للغير .

أولا: آثار عقد نقل التكنولوجيا بالنسبة لأطرافه:

إن أطراف عقد نقل التكنولوجيا على نوعين: أحدهما مستورد للتكنولوجيا، والآخر مورد لها"'، وتقتضي دراسة آثار هذا النوع من العقود بيان التزامات كل طرف نوفين منهما.

أ- التزامات مصدر التكنولوجيا:

1- الالتزام بنقل التكنولوجيا.

r- الالتزام بتقديم المساعدة الفنية.

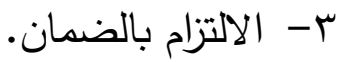

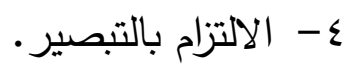

0- الالتزام بتقديم التحسينات.

7- الالتزام بالمحافظة على السرية.

(1) جلال وفاء محمدين - الإطار القانوني لنقل التكنولوجيا - ط ا ... - د دار الجامعة الجديدة للنشر - الإسكندرية - ص س آ وماء بعدها. 
ب - إلتزامات مستورد التكنولوجيا:

1- الالتزام بأداء المقابل.

$$
\text { r- (- ب الالتزام بالسرية. }
$$

r- الالتزام باستخدام عاميلن مهرة.

ع - الالتزام بإطلاع المورد الأحكام القانونية لاستيراد التكنولوجيا.

0- الالتزام بعد الترخيص من الباطل.

ثانيا: آثار عقد نقل التكنولوجيا بالنسبة للفير:

والغير هنا هم كل من ليس طرفا في عقد نقل التكنولوجيا، أي: هم الأشخاص

التي لم تتصرف إرادتهم نحو تحمل التزام معين، أو قبول أداء ما، إلا أنه على الرغم

من ذلك فمن المتصور أن يلحق هذا الغير أضرارا من جراء نقل التكنولوجيا؛ لذا

وجبت حمايتهم، وجبر ما يصيبهم من أضرار (').

وبالطبع فإن حماية الغير من أضرار نقل التكنولوجيا لا تتقرر إلا بنتظيم

تشريعي، فيجب النص عليها بنص خاص في التشريعات التى نظمت عقود نقل

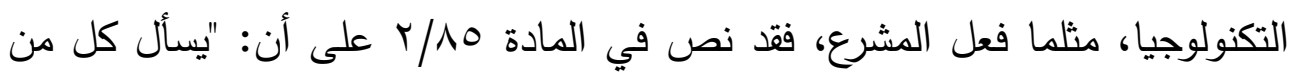

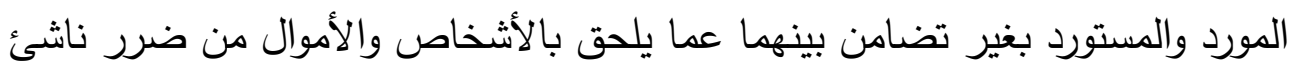

عن استخدام التكنولوجيا أو عن السلعة الناتجة عن تطبيقها".

وليس معنى أن تشريعات الدول التي لم تتناول عقود نقل التكنولوجيا بتنظيم

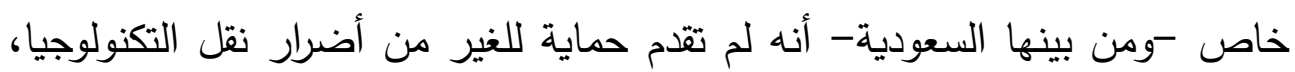
فتدخل حماية الغير في هذا الثأن تحت مظلة القواعد العامة، حيث إن قواعد المسئولية التقصيرية تحقق الغاية المنشودة في هذا الثأن.

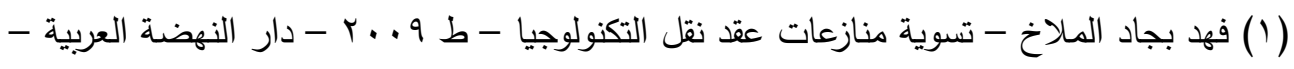
القاهرة - ص ... 
وجدير بالذكر في هذا الصدد أن المنازعات الناشئة عن إلحاق الضرر بالغير

نتيجة نقل التكنولوجيا غير متصور أن تكون محلا للتحكيم، حيث إن الغير ليس طرفا في العقد؛ ومن ثم ليس طرفا في شرط أو مشارطة التحكيم. 


\section{المبحث الثاني}

\section{ضوابط الاتفاق علي التحكيم في عقود نقل التكنولوجيا}

تقتضي دراسة ضوابط الاتفاق على التحكيم في المنازعات الناشئة عن عقود

نقل التكنولوجيا أن نعرض لمسألتين: الأولى: الشروط الواجب مراعاتها في اتفاق التحكيم في عقود نقل التكنولوجيا، والمسألة الثانية: بيان آثار الاتفاق علي التحكيم في

عقود نقل التكنولوجيا.

المطلب الأول

شروط اتفاق التحكيم في عقود نقل التكنولوجيا

أضحت العلاقات الاقتصادية الدولية -خاصة عقود نقل التكنولوجيا- تحتوي

على مجموعة من الشروط تقتضي احترام المبادئ القانونية الدولية، والتي مؤداها المساواة في العلاقات الاقتصادية؛ تحقيقا للتنمية والاستفادة من المعرفة الفنية؛ إذ يستعين المحكم بمبادئ القانون التي تعتبر عاملا مشتركا لمعظم الأنظمة القانونية، وقوام هذه المبادئ أنها ترتكز على حسن النية في التعامل، وتعويض الضرر عن

ذلك (')

وهذه المبادئ العامة في القانون الدولي تتقق في مفهومها مع ما أوردته التشريعات المختلفة في القانون المقارن من أن العقد شريعة المتعاقدين، وأن الحق في التعويض عن الضرر وغيرها، إلا أننا سنقف عند مبدأ الرضا وتنفيذ العقد بحسن ان النية، ومبدأ توازن الأداءات؛ حيث تشكل هذه المبادئ حجر الزاوية في التحكيم، ويتم تطبيقها في المنازعات المعروضة على هيئة التحكيم، ويقتضي الأمر تطبيقها على هده عقود نقل التكنولوجيا.

(1) محمود الكيلاني، الموسوعة التجارية المصرفية، م.س، صـوج؟. 


\section{أولا: مبدأ الرضا وتنفيذ العقد بحسن النية:}

إن مبدأ حسن النية تدعيم لمبدأ الحرية التعاقدية، بل هو نتيجة متفرعة عنه،

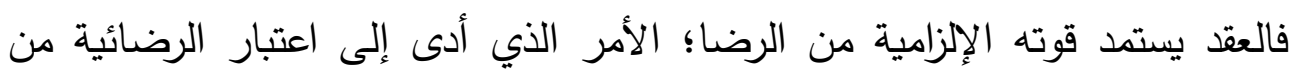
القواعد الجوهرية في القانون المدني (').

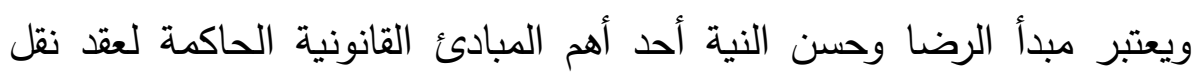
التكنولوجيا، هذا العقد المبنى على اختلال في المراكز القانونية، والتي من خلالها يمكن للمحكم أن يتدخل للحفاظ على حالة التوازن العقدي.

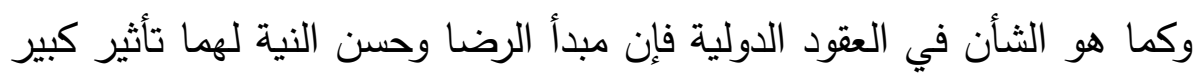

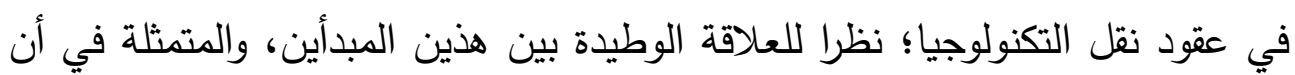
العقد شريعة المتعاقدين، وأنه يكتسب قوته الملزمة بتوافق إرادتي طرفي العقدا.

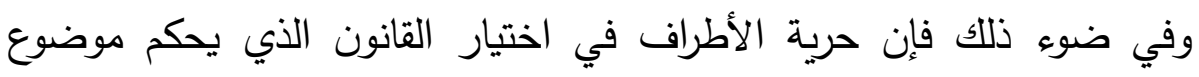

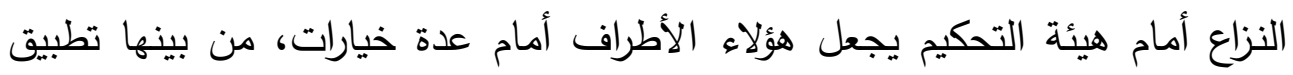

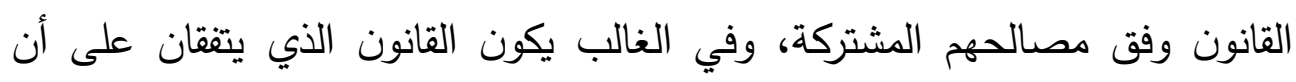

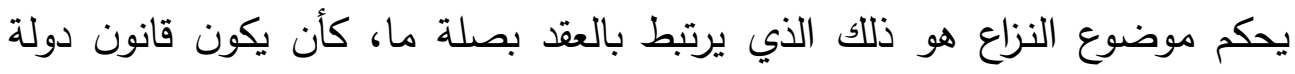

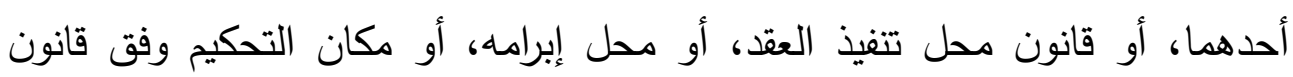

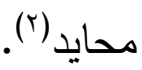

ويدخل ضمن مبدأ الرضا وتتفيذ العقد بحسن النية حرية المتلقي في بيع

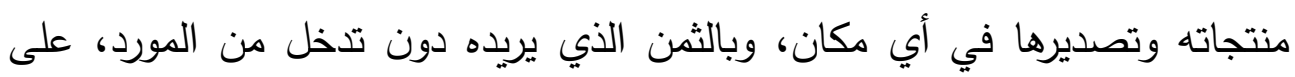

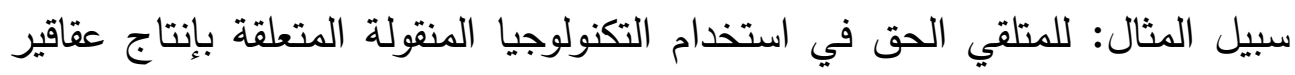

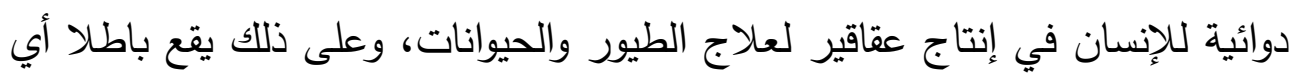

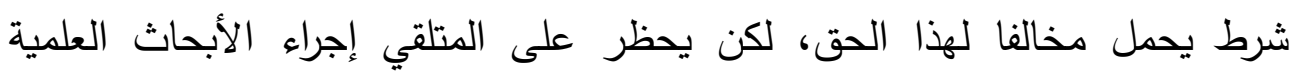
والتحسينات لتطوير التكنولوجيا وفق احتياجاته المحلية أو إجراء الأبحاث التي لهي التئي

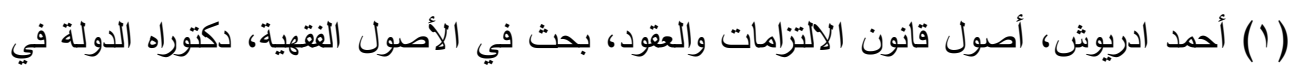

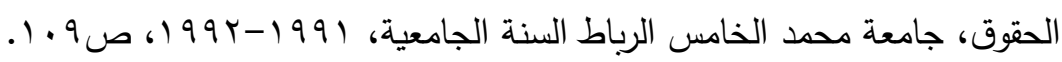

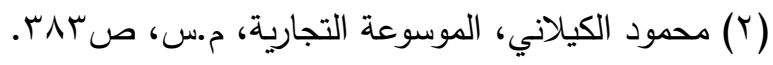


تستهدف منتجات جديدة، وسبب الامتثال إلى مثل هذا الإلزام هو الرابطة العقدية التي

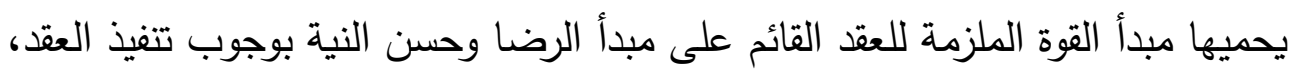
وعدم قدرة المتعاقد أن يرجع عن هذا التنفيذ في مثل هذه العقود. ويشترك الرضا وحسن النية في تحديد حرية الأطراف على موضوع النزاع؛ إذ تتجه إرادة الأطراف إلى تحديد القانون بناء على قواعد القانون الدولية، وقد ذهبت المادة السابعة من الاتفاقية الأوروبية المتعلقة بالتحكيم التجاري الدولي إلى أنه: "للأطراف حرية تحديد القانون الواجب التطبيق على موضوع النزاع، وفي حالة وجود إثارة للقانون الواجب التطبيق يقوم المحكمن بتطبيق القانون الذي تعينه قاعدة تتازع القوانين التي تراها مناسبة، وفي الحالتين يأخذ المحكمون في الاعتبار اشتراطات العقد، والأعراف الثائع استخدامها في مجال التجارة". ويبقى مبدأ الرضا وحسن النية من المبادئ الأساسية في عقد نقل التكنولوجيا؛ لما يتميز به هذا العقد من خصوصيات، وغلبة الطابع السري على موضوعه ومحله،

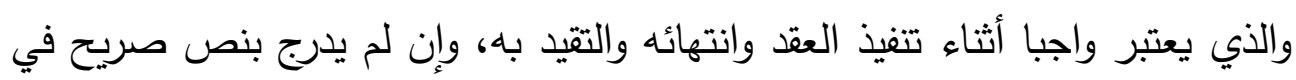
العقد، كما أنهما من المبادئ التي يرتكز عليهما في تكوين العقد وتفسيره. لكن رغم ذلك يبقى مبدأ الرضا وحسن النية مقيدين بمجموعة من الثروط، عندين والتي تعتبر من التظظيمات القانونية الخاصة التي أدت إلى اختلال نظام التوازن العقدي الذي يقيد من حرية الإرادة، لكن هذا لايمنع الأطراف المتعاقدة من اختيار القانون الواجب التطبيق، والاتفاق على تسوية المنازعات، طبقا لمقتضيات معاهدة جنيف للتحكيم الموقعة سنة ال197 والتي تقتضي أنه :"للأطراف حرية تحديد القانون الذي يجب على المحكمين تطبيق أحكامه على موضوع النزاع"، إلا أن الأمر ليس علي إطلاقه في القانون السعودي، حيث إن المشرع السعودي قيد هذا الأمر بعدم المخالفة لأحكام الثريعة الإسلامية. وليس هناك مجال لحرية المحكمين في تحديد قانون العقد وتطبيقه إلا في غياب الاختيار الصريح للقانون الواجب التطبيق من جانب المتعاقدين، فتطبيق 
القانون الذي يختاره المتعاقدون يمثل أحد المهام المنوطة بالمحكم الذي يجب أن يلتزم بأدائها(')، وبالتالي فإن المشرع الدولي عمل على الأخذ بمبدأ سلطان الإرادة في اختيار القانون الواجب التطبيق، بحيث أعطى الحرية للأطراف المتعاقدة في تحديد القانون الواجب التطبيق، وفي حالة عدم اتفاق الأطراف على تحديد هذا القانون، وغياب التعبير الصريح لهذه الإرادة؛ يتم الرجوع إلى الأعراف الثائع استخدامها في التئي مجال التجارة الدولية؛ إذ تعتبر هذه الأخيرة من ضمن القواعد الدولية الواجب احترامها والامتثال لها؛ لأن عقد نقل التكنولوجيا يتأثر بالظروف المحيطة بالعلاقات الدولية؛ ضمانا لاستمرار العلاقات التعاقدية والتعاون الدولي في مجال النقل التكنولوجي؛ لأنه متأثر بالعوامل السياسية والاقتصادية أكثر من تأثره بالمبادئ القانونية الدولية. ثانيا: مبدأ توازن الالتزامات: باتئرل يكتسب مبدأ توازن الأداءات أهمية بالغة، سواء على مستوى التشريعات الوطنية، أم على مستوى المبادئ القانونية الدولية، بما يضمن المساواة في العلاقات التعاقدية، وحماية للطرف الضعيف، وغالبا ما يتم توجيه هذا المبدأ للدول النامية (دول الجنوب) بحكم مركزها القانوني الضعيف أمام الدول الصناعية (دول الشمال). ومفاد هذا المبدأ تطبيق مجموعة من الحقوق والالتزامات المنشئة في العقد، إضافة إلى مجموعة من الشروط المدرجة في بنود العقود؛ مما يجعل هذه التصرفات

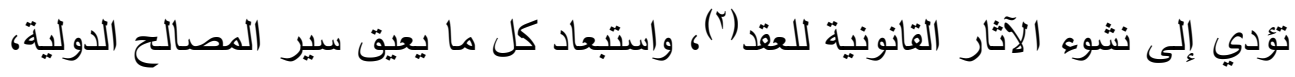
ووضع التدابير الوقائية للحفاظ على النظام العام الاقتصادي، والإقرار بمعاملة تفضيلية للدول النامية بهدف تشجيع الاستثمارات ونقل التكنولوجيا. لذلك فإن الأصل هو إقرار مبدأ توازن الالتزامات في مجال نقل التكنولوجيا للحد من المخاطر الاقتصادية التي يواجهها المستورد، ويحميه من الاضطرابات

(1) صلاح الدين جمال الدين، عقود نقل التكنولوجيا، تتازع القوانين وتسوية المنازعات (... ب،

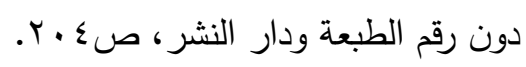

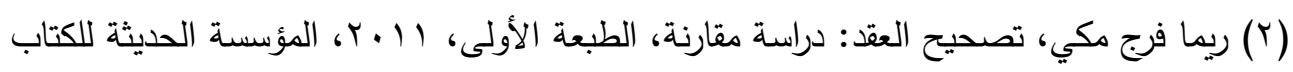

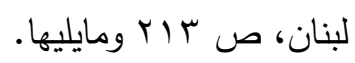


التشريعية التي يواجهها من قبيل الظروف الطارئة التي تجعل تتفيذ الالتزام الناشئ في العقد مرهقا للمدين، حيث استطاع قضاء التحكيم بفضل هذا الشرط أن يقوم بتصحيح العقد، ويدخل تعديلات عليه؛ استتادا لهذا المبدأ.

كما أن المحكم الذي يعرض عليه النزاع الناتج عن عقد نقل التكنولوجيا الذي اختل توازنه الاقتصادي يجب عليه أن يأخذ بعين الاعتبار مبدأ المحافظة على توازن الالتزامات التعاقدية، الذي يعد جزءا مهما في قانون التجارة الدولية، وأن يظهر قدرا كبيرا من المرونة التي ينبغي أن يثبتها بموجب هذا القانون، باعتباره الكاشف عن فئن قواعده، تلك المرونة التي غابت عن أذهان مشرعي الأنظمة القانونية الوطنية وقضاتهم، الذين تعاملوا مع مشكلة التغير في الظروف المحيطة بتنفيذ العقد من منظور العقود الفورية التتفيذ، مقدمين حلولا لحالة الاستحالة، وإن كانت لا توصف بالمرونة، ومتثددين في جانب مهم عند التعامل مع الوضع الذي تتطلب فيه اقتصاديات العقد ذلك ('). برونهاهن.

وإذا كان الأصل أن "العقد شريعة المتعاقدين"، والركيزة الأساسية للتصرفات

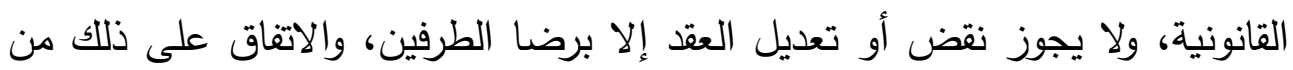
الجانبين، سواء أمام هيئة التحكيم، أم إدراج ذلك في بنود العقد للحفاظ على مبدأ توازن الالتزامات؛ فإنه في نطاق عقد نقل التكنولوجيا والهيمنة الاقتصادية، وأمام عجز إتهاء التنظيمات التشريعية عن مواجهة التطورات التي تعرفها التجارة الدولية؛ فإن هذه المبادئ يتم الرجوع لها باعتبارها من عناصر القانون التجاري الدولي المتمتع بالقوة الملزمة للعقد، والتي يتم الاحتكام لها بغض النظر عن إرادة المتعاقدين، كما أن قضاء التحكيم قد استطاع في التطبيق العملي أن يضفي على هذه المبادئ ذاتيتها المتفقة وطبيعة التجارة الدولية، ذاك أن نظرية الظروف الطارئة في المبادئ العامة للقانون تعطي للقاضي سلطة تعديل العقد، أما في مجال التحكيم الدولي -وطبقا لمبادئ

( (1) مراد محمود المواجدة، المسئولية المدنية في عقود نقل التكنولوجيا م.س، صج9 §. 
القانون الدولي- فيتم تقييد سلطة المحكم في تعديل العقد في العقود الطويلة المدى، كعقد المفتاح في اليد الذي يعد صورة من صور عقد نقل التكنولوجيا، بحثا عن الحلول المناسبة لحل النزعات القائمة عبر الحدود. المطلب الثاني: آثار اتفاق التحكيم في عقود نقل التكنولوجيا: إن نتيجة تمتع الأطراف بحرية اختيار القانون الواجب التطبيق على العقد حريتهم، وقدرتهم على تجميد القانون المادي الذي اختاروه، وهو ما يؤدي إلى إفلات العقد من الخضوع للآثار الناجمة عن التغييرات التشريعية التي قد تطرأ على هذا القانون المختار للتطبيق على العقد ('). كما أن الخصوصية التي تمتاز بها عقود نقل التكنولوجيا -كونها متعلقة بالاستثمارات وخطط التنمية- تتطلب وجود قواعد قانونية تراعي الطبيعة الخاصة لهذه العقود، مثل حالة تطبيق المبادئ العامة عبر الدولية التي تحرم الثركات المتعددة الجنسيات من التستر خلف الشكليات القانونية للتصصل من التزاماتها(؟). ومن الآثار القانونية المترتبة عن هذه العقود(؟) سنعرض آثار اتفاق التحكيم بالنسبة للأطراف المتعاقدة (الفرع الأول) وآثار اتفاق التحكيم بالنسبة للمحكم (الفرع الثاني). الفرع الأول: آثار اتفاق التحكيم بالنسبة للأطراف المتعاقدة:

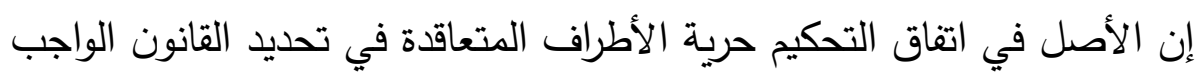
التطبيق علي العقد، ومن الطبيعي أن يكون هذا القانون هو الحاكم للعقد بما يطرأ عليه من تعديلات تشريعية، وتخطيا لكل قيد يعرقل مسيرتهم التعاقدية، وفق مبدأ العقد شريعة المتعاقدين، لكن الاستثناء يقع في عقود نقل التكنولوجيا، فتصبح إرادة الأطراف

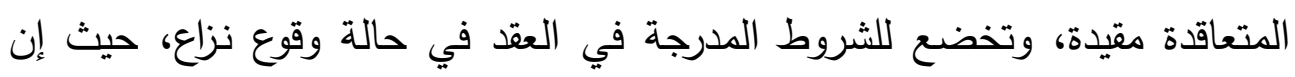

(1) حفيظة السيد الحداد، العقود المبرمة بين الدول والأثخاص الأجنبية: تحديد ماهيتها والنظام

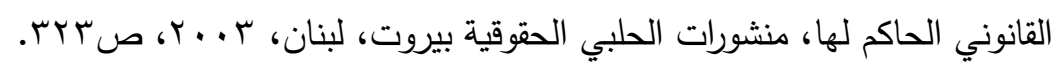

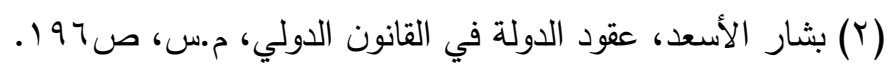
(r) انظر في هذا البحث المطلب الثاني من المبحث الأول. 
الأطراف تجد إرادتها مقيدة أمام مجموعة من الشروط التي لا يمكن تجاوزها أو استبعادها؛ إذ يتم تقييد حرية الأطراف بما ورد في الاتفاق بمجموعة من الشروط المقيدة التي لايجوز مخالفتها حسب بنود العقد، فيتم تقييد حرية الأطراف بما ورد في الاتفاق كما يتعلق الأمر بالتجميد الزمني لقانون العقد، إذا قام الأطراف بإدراج اتفاقات

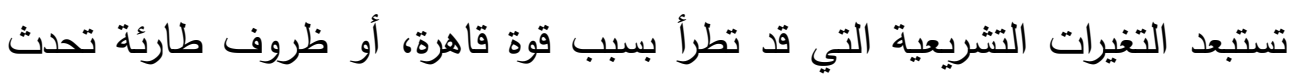
مستقبلا، وهو ما يعرف بشرط الثبات التشريعي. أولا: تقييد حرية الأطراف بما ورد في الاتفاق: إن واجب احترام الأطراف لمضمون العقد يجد أساسه في مبدأ العقد شريعة المتعاقدين، ووجوب احترام هذه القاعدة يجد أساسه في القوة الملزمة للعقد، والتي لا تتحصر على الأطراف في العلاقة التعاقدية، بل تمتذ للقاضي والمحكم، وفي ظل التغيرات الاقتصادية التي شهدتها الأنظمة القانونية المعاصرة، وتخطيها للحدود العابرة، وارتباطها بالمحيط الدولي الخارجي؛ أصبحت العلاقات القانونية في مجال العقود الدولية -خاصة النقل التكنولوجي- لم تعد تلائم التكييف القانوني بسبب تقييد حرية الأطراف، وفي ذلك نص المشرع المصري في المادة ه من قانون التجارة المصري على أنه: "يجوز إبطال كل شرط يرد في عقد نقل التكنولوجيا، ويكون من شأنه تقييد حرية المستورد في استخدامها، أو تطويرها، أو تعريف الإنتاج، أو الإعلان عنه، وينطبق ذلك بوجه الخصوص على الشروط التي يكون موضوعها إلزام المستورد

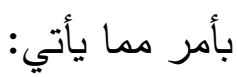
(أ) قبول التحسينات التي يدخلها المورد علي التكنولوجيا وأداء قيمتها. (ب) حظر إدخال تحسينات أو تعديلات على التكنولوجيا لتلائم الظروف المحلية، أو

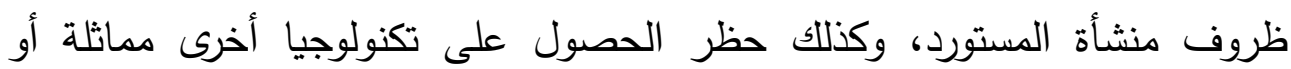
منافسة للتكنولوجيا محل العقد. (ج) استعمال علامات تجارية معينه لتمييز السلع التي استخدمت التكنولوجيا في 


\section{(د) تقييد حجم الإنتاج، أو ثنه، أو كيفية توزيعه، أو تصديره.}

(ه) اشتراك المورد في إدارة منشأة المستورد، أو تدخله في اختيار العاملين الدائمين

(و) شراء المواد الخام، أو المعدات، أو الآلات، أو الأجهزة، أو قطع الغيار لتشغيل التكنولوجيا من المورد وحده، أو من المنشآت التي يعينها دون غيرها. (ز) قصر بيع الإنتاج أو التوكيل في بيعه على المورد، أو الأشخاص الذين يعينهج، وذللك كله ما لم يكن أي من هذه الشروط قد وردت في عقد نقل التكنولوجيا بقصد التصد حماية مستهلكي المنتج، أو رعاية مصلحة جديدة ومشروعة لمورد التكنولوجيا". من خلال هذه المادة حاول المشرع المصري أن يشترط على المستورد استخدام التكنولوجيا في مجالات محصورة، ذاك أن المورد (مصدر التكولوجيا) لما له من احتكار وقوة اقتصادية يستطيع أن يضغط على متلقي التكنولوجيا، ويتدخل في شئونه الاقتصادية، ومنعه من التصنيع والإنتاج وإدخال التحسينات على التكنولوجيا المنقولة، والمنافسة داخل الأسواق الوطنية والدولية إلا في الحدود التي يرسمها المورد؛ مخافة

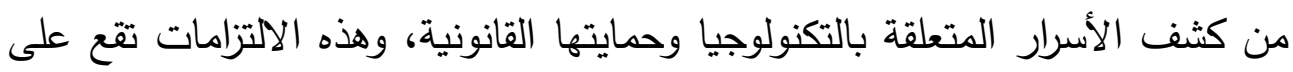
عاتق المستورد، سواء في مرحلة التفاوض، أم مرحلة تتفيذ العقد، ومخالفتها ترتب الآثار القانونية، وما يترتب علي ذلك من توقيع الجزاء المدني. إن إرادة الأطراف تكون مقيدة بالشروط المدرجة في العقد، وفي حالة الإخلال بالالتزامات الملقاة على عاتق الطرفين يكون لكل منهما اللجوء إلى المطالبة بحقوقه في حالة إلحاق الضرر على أحد الطرفين الذي يرتب المسؤولية المدنية؛ لذلك وجب إنى الاحتياط في التعامل مع عقود نقل التكنولوجيا، سواء تعلق الأمر بحماية الأسرار التجارية، أم حظر إدخال تحسينات أو تعديلات على التكنولوجيا، أم بشرط القصر ، أم غيرها من الشروط التي يتم إدراجها في عقد نقل التكنولوجيا، وهي تعتبر شروطا مقيدة، وبالتالي الأطراف المتعاقدة تمتثل لها، سواء في مرحلة التفاوض، أم بعد إبرام

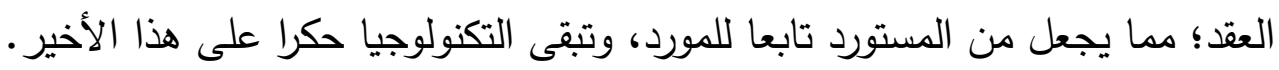




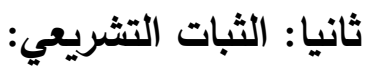

إذا نص الأطراف على أن قانون الإرادة الذي يسري على العقد عند نشوء نزاع

هو القانون المختار بأحكامه وقواعده النافذة أثناء إبرام العقد مع استبعاد تطبيق أي الي التيات

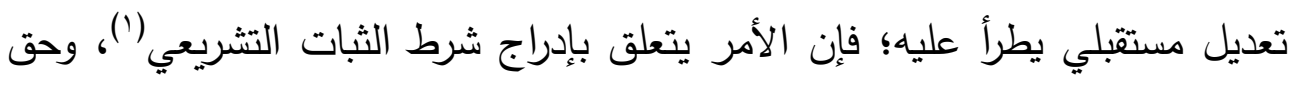

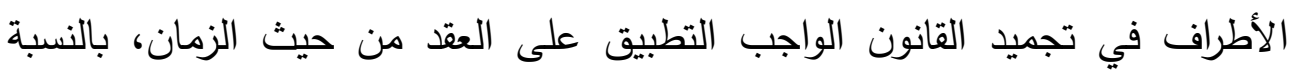

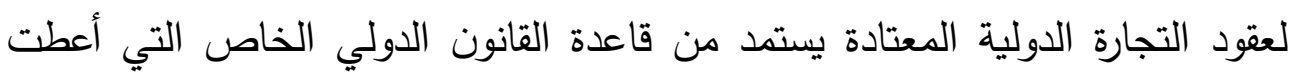

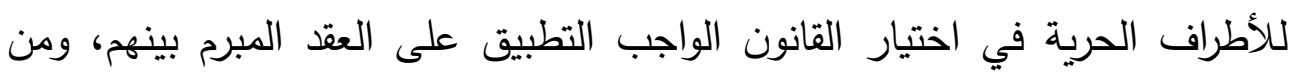
الأهداف التي تسعى هذه القاعدة إلى تحقيقها (†). وبهذه المثابة يكون الباعث إلى تجميد القانون المختار الواجب التطبيق أن هذا لتاعيأ

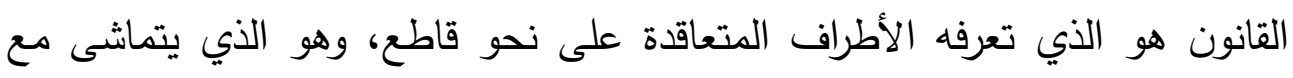

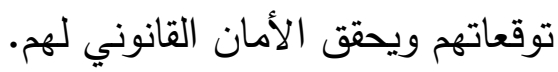

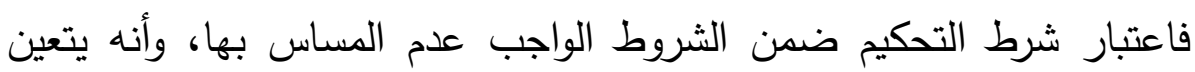

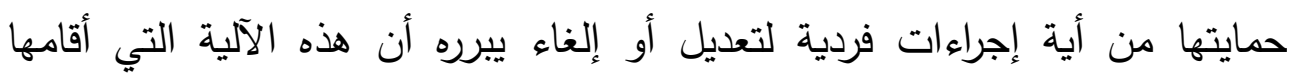

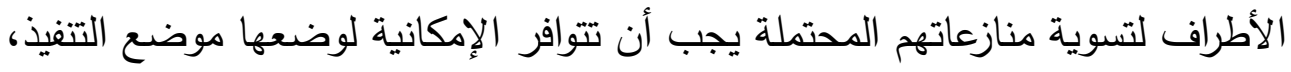
وذللك لتقدير مشروعية الإجراءات ونتائجها التي تقدم عليها الدولة ممارسة لسلطاتها

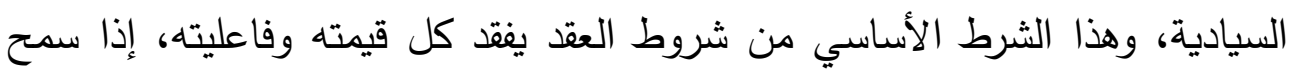
لللدولة أن تتحلل منه بإرادتها المنفردة. وقد اعتمدت العديد من الدول النامية تبني شرط الثبات التشريعي التي تضمن باتئن

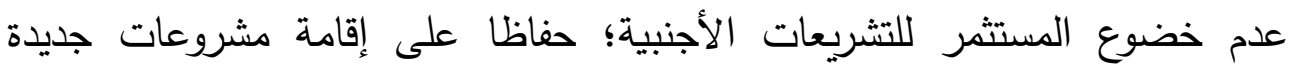

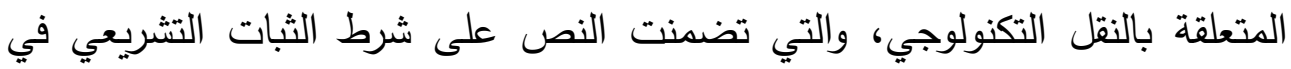

(1) أحمد عبد الكريم سلامة، شروط الثبات التثريعي في عقود الاستثار والتجارة الدولية، المجلة

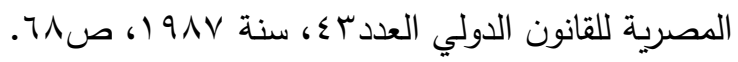

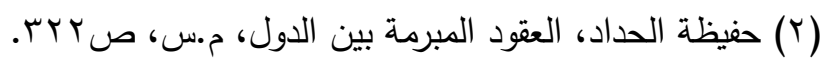


أحكامها، وتبنتها كنصوص قانونية لا يجوز مخالفتها، أو الاتفاق على ذلك، مهما كان حجم التعديلات التي تطرأ على هذه القوانين، أو ما تتتجه من آثار. ومن المبادئ المعترف بها في القانون الدولي العام أن الدولة عندما ترتبط بشرط تحكيم ينص عليه في عقد مبرم بواسطة الدولة ذاتها، أو من خلال جهاز تابع لها لا يمكنها بإرادتها المنفردة في تاريخ لاحق أن تمنع الطرف الآخر المتعاقد معها

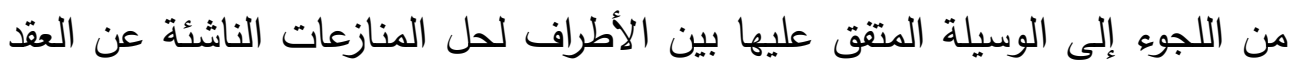

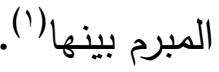
وشرط الثبات التشريعي عبارة عن نصوص تشريعية وردت في صلب قانون الدولة التي ستدخل طرفا في عقد أو اتفاق دولي مع شخص خاص أجنبي، بمقتضاها

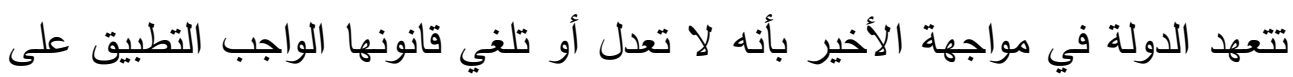
العقد أو على الاتفاق(؟).

وإن كانت هناك بعض أحكام القضاء الوطني قد أقرت على هذا النحو مبدأ ثبات قانون الإرادة وقت إبرام العقد، وعدم الاعتداد بالتشريعات اللاحقة، فإن هناك أحكام المحكمين التي باركت شرط الثبات التشريعي، حيث أصبحت فكرة التجميد الزمني لقانون الإرادة طبيعية تماشيا مع الاتجاه المعاصر في قضاء التحكيم نحو لباءئ

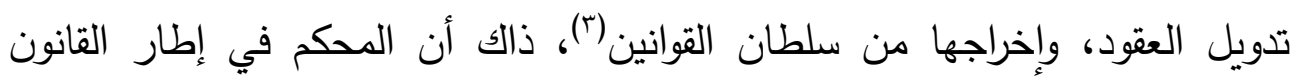
الدولي العام-باعتباره القانون الذي يحكم اتفاق التحكيم- يستطيع -إذن - أن يتغافل

(1) حفيظة السيد الحداد، العقود المبرمة بين الدول والأشخاص الأجنبية، م.س، ص •19 ـ

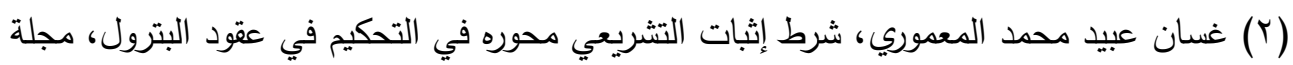

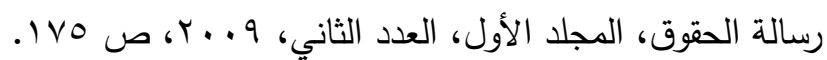
(r) هشام صادق، القانون الواجب التطبيق على عقود التجارة الدولية: دراسة تحليلية ومقارنة

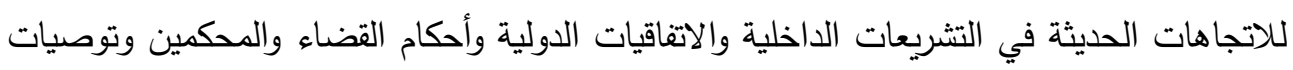
مجمع القانون الدولي، مع إشارة خاصة لموقف المشرع المصري، سواء في التقنين المدني وفي ولئي

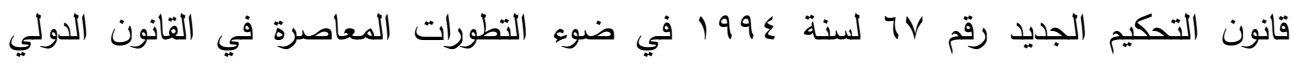

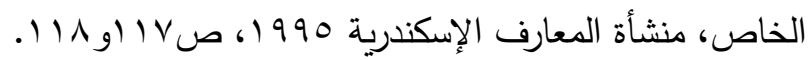


عن تللك التعديلات التي طرأت في القانون الداخلي للدولة المتعاقدة، والتي تمس الاتفاقات التحكيمية التي أبرمتها... فهذا الأخير لا يستمد في هذا الغرض قوتي لتهي الملزمة من قانون هذه الدولة، وإنما من القانون الدولي العام مباشرة. وإذا تم عدم إدراج شرط الثبات التشريعي في عقود نقل التكنولوجيا بحجة وجود أبعاد قانونية تتمثل في استبعاد خطر حدوث المفاجآت والتي أقرها التحكيم، وتدخل في إطار قواعد النظام القانوني الجديد والمتعلقة بإمكانية مراجعة العقد، لا سيما إذا ما تعلقت العلاقة بعقد يستغرق تتفيذه فترة زمنية طويلة، والتي تتيح للمحكم بناء على اتفاق الأطراف إمكانية تعديل شروط العقد؛ حتى تلائم الظروف الاقتصادية الجديدة وفق صيخ توضح كيفية تسوية المنازعات الناشئة، وذلك في الحالات التي تتوافر فيها الظروف الطارئة أو القوة القاهرة بوضع حلول تتهي من هذه الآثار؛ كي لا ينهار العقد، وهو ما يجعل وجود فرق بين التجميد الزمني لقانون العقد من الناحية التشريعية والتجميد الزمني بناء على شرط الثبات الاتفاقي يكون من قبيل النتيجة الطبيعية لقانون الإرادة في العقد واعتبار أحكامه مجرد شروط تعاقدية('). أما حينما تتعهد الدولة بعدم تعديل قوانينها الجارية عند إبرام الاتفاق مع ناقل

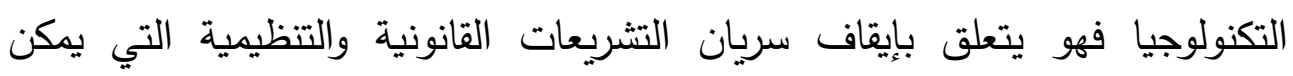
إصدارها بعد إبرام العقد؛ وذلك حفاظا على الاستقرار للروابط العقدية، وبعث الأمن القانوني للمستثر الأجنبي في هذا المجال. وما يمكن قوله إن نظرية العقد تقوم في مجملها على أساس مبدأ سلطان الإرادة الذي يعني حرية طرفي الرابطة العقدية في تضمين اتفاقهم بالحقوق والالتزامات التي اتجهت إليها إرادتهم المشتركة، لكن في عقود نقل التكنولوجيا فإن هذه الالتزامات تستغرق سنوات عديدة تجعل من الصعب تحديد المراكز القانونية لطرفيه، كناقل التكنولوجيا الذي قد تفرض عليه ضرائب مالية بخصوص هذا النقل، ويكون قد تم

(1) هشام صادق، القانون الواجب التطبيق على عقود التجارة الدولية، م.س، ص911 1 . 
تحديدها عند تنفيذ العقد، لكن نتيجة للظروف تم إصدار قوانين ترفع من قيمة هذه الضرائب.

وتجدر الإشارة إلى أن مشكلة التغييرات التشريعية وأثرها على اتفاق التحكيم في مجال عقود نقل التكنولوجيا قد تؤدي إلى زعزعة الثقة بين المتعاقدين، والإخلال بقواعد الأمن القانوني والأمن الاقتصادي؛ مما يسهم في تحقيق التنمية المستدامة، والحصول على المعرفة الفنية، من خلال إطار قانوني واضح يحكم العلاقات الاقتصادية الدولية، ويرتب المسئولية المدنية في حالة عدم تنفيذ الالتزامات، لذلك فالتغييرات التشريعية في مجال عقد نقل التكنولوجيا يجب ألا تصدر بطريقة فجائية مباغتة تصطلم مع النتائج التي يتوخاها الأطراف؛ حفاظا على المراكز القانونية، وعدم المساس بها كي لا تزيد من اخلال التوازن الاقتصادي للعقد.

لذلك فإن شرط الثبات التشريعي يحاول أن يحد من هذه التوقعات المفاجئة، حيث يتم استبعاد التعديلات الجديدة التي قد تطرأ على العقد؛ حماية لناقل التكنولوجيا، مثل فرض التزامات جديدة بزيادة نسبة الضرائب مثلا أثناء تتفيذ العقد، ويكون هذا القانون الجديد يؤثر على التزامات المتعاقد، لذلك يتم اعتماد هذا الشرط توفيرا لثبات الظروف الاقتصادية المحيطة بالتعاقد مما يوفر لناقل التكنولوجيا قدرا كافيا من الحماية التي تتطلبها طبيعة هذا التعاقد. الفرع الثاني: آثار اتفاق التحكيم بالنسبة للمحكم: يثير التحكيم في عقود نقل التكنولوجيا مجموعة من المشكلات القانونية المتعلقة بحدود سلطة المحكم في التصدي للنزاع المطروح، وحدود سلطته في احترام اتفاق التحكيم، وتطبيق القانون الواجب التطبيق، أي: هل سلطته مطلقة أم مقيدة بأحكام القانون الواجب التطبيق وإرادة الأطراف واتفاقهم؟ حيث إن المحكم إذا لم يلتزم باتفاق الأطراف والقانون الواجب التطبيق يكون قد خرج عن القواعد القانونية ومبادئها، تلك الإرادة التي تعتبر أساس إعفاء المحكم من تطبيق القانون، لذلك هل اتفاق الأطراف واحترام إرادتهم يلزم المحكم ويقيد حريته؟ أو أن المحكم له الحق في تطبيق قواعد 
القانون التجاري الدولي من مبادئ القانون الدولي والأعراف التجارية؟ أو له الحرية

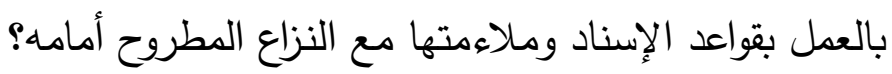
للاجابة على هذه التساؤلات نعرض لنقطتين: الأولى: سلطة المحكم في احترام اتفاق التحكيم، والثانية: متعلقة بسلطة المحكم في تحديد القانون الواجب التطبيق. أولا: سلطة المحكم في احترام اتفاق التحكيم: الأصل أن حرية إرادة الأطراف في الاتفاق على القواعد التي تحكم إجراءات التحكيم، ولكن قد يحدث ألا يكون هناك اتفاق بين الأطراف على تتظيم المسائل الإجرائية، أو يتفق الأطراف على تفويض هيئة التحكيم في اختيار القانون الواجب التطبيق، فهيئة التحكيم تتمتع بنفس الحرية، أو الإمكانية التي كانت للخصوم في هذا الثأن، ففي هذه الحالات لهيئة التحكيم أن تضع بنفسها ولنفسها القواعد الإجرائية التي ترى أنها الأنسب لظروف النزاع|(') ذاك أن مبدأ الرضائية يخول للأطراف المتعاقدة الحرية في تحديد القانون الواجب التطبيق. وقد أخذت اتفاقية واشنطن لسنة 970 أفي المادة بع في فقرتها الأولى على أنه: "تحكم المحكمة في النزاع وفقا للقواعد القانونية التي يتفق عليها الطرفان"؛ مما يتعين على المحكم احترام اتفاق الأطراف وعدم مخالفته.

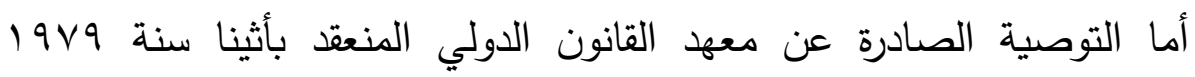
أعطت الحرية للأطراف في اختيار القانون الدولي كقانون واجب للتطبيق، وبالتالي فإن المحكم يلتزم بتطبيق هذا القانون كما هو وبنصوصه المتعلقة بالنظام العام، حتى لو كانت فيها مخالفة لنصوص العقد، فالقانون المختار على هذا النحو هو القانون المختص بالرابطة العقدية، وإعمال القواعد ذات التطبيق الضروري في هذا القانون لا

(1) معين عمر المومني، هيئة التحكيم ودورها في تحديد القانون الواجب التطبيق على الإجراءات

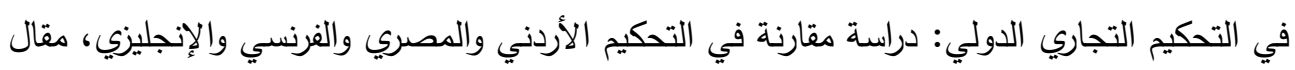

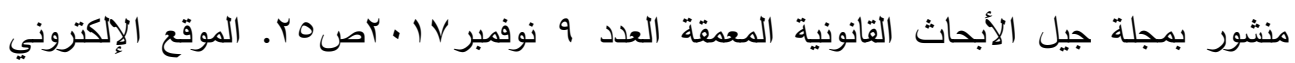

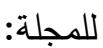
jilrc//:http-magazines.com 
يشكل مفاجأة للمتعاقدين، ولا يخل بتوقعاتهم المشروعة، فالطابع الاتفاقي يقتضي حرص المحكمين على احترامها ('). وهذا ما تذهب إليه أحكام المحكمين، حيث ترجح إعمال قواعد البوليس السائدة في الدولة التي يتوقع الأطراف تطبيق قانونها، فإذا تبين للمحكم أن قاعدة من قواعد

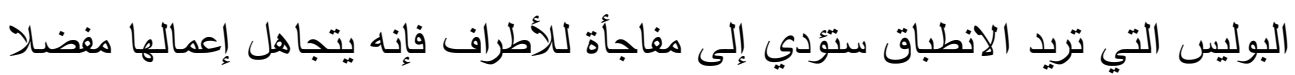
الرجوع إلى القاعدة التي لا تتاهض توقعاتهم، فالمحكمون يستمدون اختصاصهم من إرادة الأطراف، فهم يحاولون قدر طاقتهم ألا يتصدوا لوضع حلول تشكل مفاجأة لهذه

الإرادة احتراما لليقين القانوني (r). أما عند سكوت الأطراف المتعاقدة عن اختيار القانون واجب التطبيق فإن المحكم يطبق قواعد الإسناد التي يراها ملائمة لحل النزاع، وفي هذه الحالة قد يعتتق الأطراف نظاما مزدوجا عند إسناد عقد نقل التكنولوجيا. ثانيا: سلطة المحكم في تحديد القانون الواجب التطبيق: يلتزم المحكم بتطبيق القانون الواجب التطبيق على موضوع النزاع، وذلك في حالة اختيار الأطراف للقانون الواجب التطبيق، لكن عند غياب إرادة الأطراف وسكوتهم عن القانون الواجب التطبيق فإن سلطة المحكم تمتد، ويحق له اختيار هذا القانون، ذاك أن المحكم غير ملزم بإعمال قواعد الإسناد، كما هو الثأن للقاضي الذي يظل مقيدا باتباع القواعد القانونية لقانون دولته، ويتعين عليه إعمال قواعد الإسناد التي تمكنه من تحديد القانون الواجب التطبيق. ذاك أن المحكم الدولي ليس له قانون اختصاص، ولا يصدر أحكامه باسم أية دولة مقارنة، وغير مقيد باتباع منهج تتازع القوانين في قانون معين ليتحدد على ضوئه القانون الذي يحكم موضوع النزاع، وإنما هو ملزم بتحديد القانون الذي لا ينافي توقعات الأطراف المتعاقدة، ولا يشترط عليه في سبيل ذلك اتباع طريقة محددة

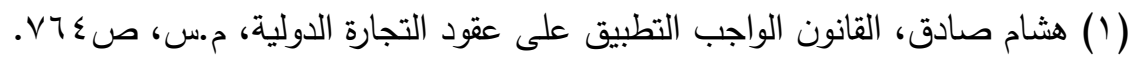
(Y) هشام صادق، مدى سلطة المحكمين في إعمال القواعد ذات التطبيق الضروري، مقال منشور

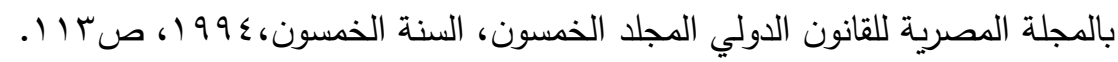


بذاتهال'، وبالتالي يجب على المحكم الالتزام بشروط العقد والقانون الواجب التطبيق، فإذا جاء عقد نقل التكنولوجيا خاليا من شرط يجيز لهذا المحكم التدخل بالتعديل، ولا يسمح لله القانون الواجب التطبيق بذلك فإنه يمتنع عليه التذخل، أي: أن سلطة المحكم بالقانون مقيدة بنصوص العقد، وبنصوص القانون المطبق على هذا العقد، وذللك دون المساس بالنظام العام للدولة التي يجري قرار التحكيم على إقليمها، والالتزام بقواعد الحياد الواجب توافرها لدى المحكم. أما إذا لم يقم المتعاقدون باختيار القانون الواجب التطبيق صراحة فيكون للمحكم الحق في استظهار إرادة الأطراف الضمنية، والكثف عنها لاختيار قانون العقد؛ إذ تبقى للمحكم سلطة التحديد المباشر للقانون الواجب التطبيق على موضوع النزاع المطروح أمامه دون الالتزام بالأخذ بنظام تتازع معين للوصول عن طريقه إلى

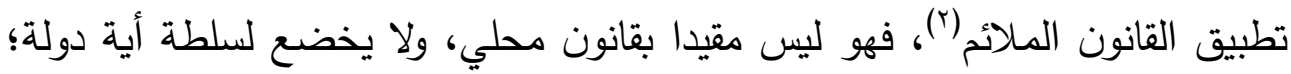
إذ يستمد سلطته من إرادة الأطراف، فهو غير ملزم باحترام المفاهيم الوطنية، ويكون ملزما باحترام المفاهيم الدولية، ولهذا فهو غير مكلف من قبل الدولة بتطبيق قوانينها، وغير ملزم بتطبيق قواعد النظام العام. والتحكيم -وفقا للقانون - يقتضي من المحكم أن يتعرف على وقائع النزاع، وأن يبحث عن القواعد الموضوعية في القانون الواجب التطبيق التي تتولى حسم النزاع، مراعيا بذلك القواعد الآمرة وشروط العقد (ז)، ولا يمكنه اللجوء إلى المبادئ القانونية

(1) أشرف عبد العليم الرفاعي، القانون الواجب التطبيق على موضوع التحكيم والنظام العام في

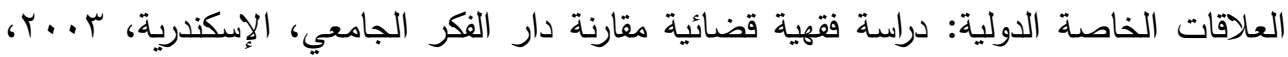

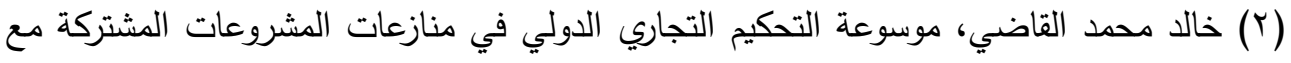
إثارة خاصة لأحدث أحكام القضاء الدصري، الطبعة الأولى ب....r، دار الشروق القاهرة،

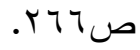

(ץ) جعر مشيمش، التحكيم في العقود الإدارية والمدنية والتجارية: دراسة مقارنة، الطبعة

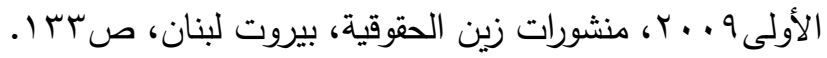
- ITV_ 
الدولية إلا إذا لم يجد نصا خاصا يتضمن حلًا للنزاع المطروح عليه، كما هو الثأن

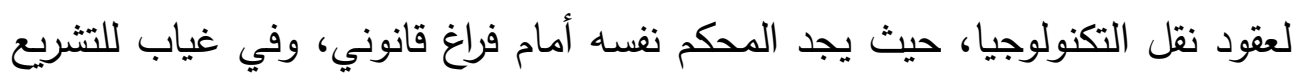
الوطني الذي يمكنه الاعتماد عليه في تطبيق قراراته، وعدم وجود إرادة صريحة

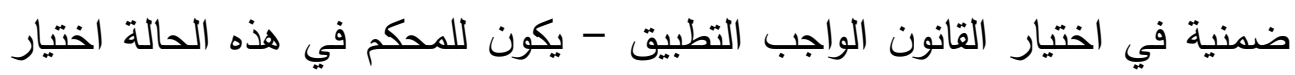

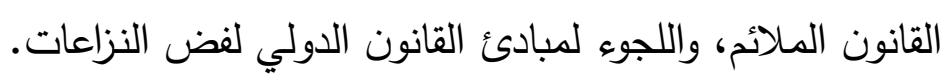

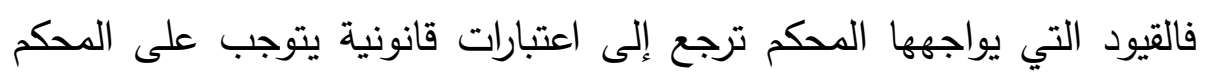

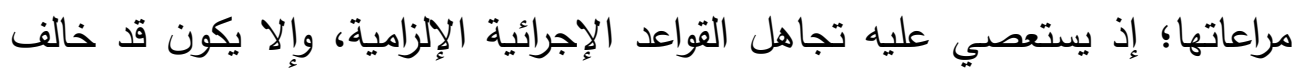
تللك القواعد في قانون محل تتفيذ الحكم، ويصبح حكمه باطلا ومخالفا لها.

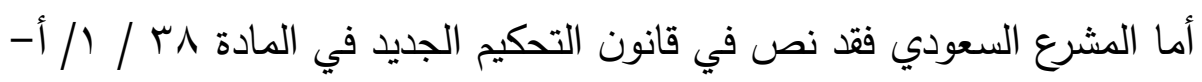

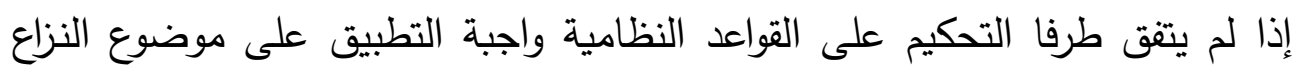
طبقت هيئة التحكيم القواعد الموضوعية في النظام الذى ترى أنه الأكثر اتصالا بموضوع النزاع.

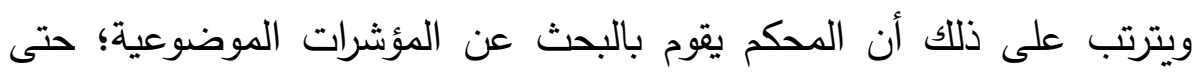

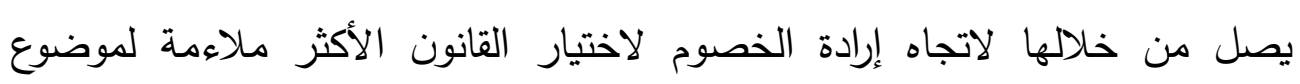

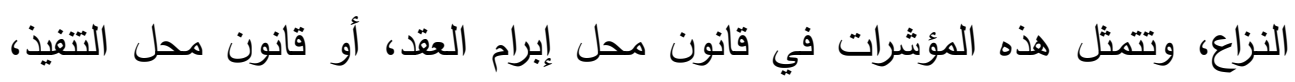

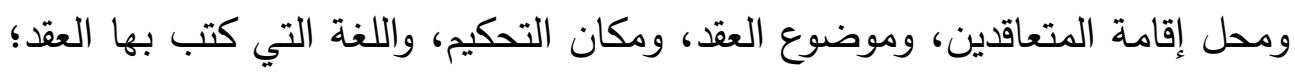

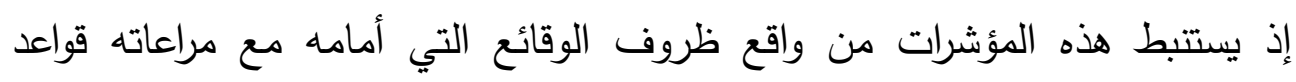
الأعراف التجارية والمبادئ القانونية الدولية. 


\section{الخاتمة}

إن تعزيز التعاون الدولي واكتساب النقل التكنولوجي من المشكلات التي تواجهها الدول النامية بشكل خاص، لاسيما ما تعرفه من صعوبات بفعل تفاوت المراكز القانونية والهوة الاقتصادية - يجعل من عقود نقل التكنولوجيا في حاجة ماسة إلى تبني تشريعات قانونية قوية من شأنها تسهيل الوصول إلى التكنولوجيا، والحصول عليها.

وفي ظل الفراغات التشريعية في هذا المجال فمن السهل نشوء مشكلات

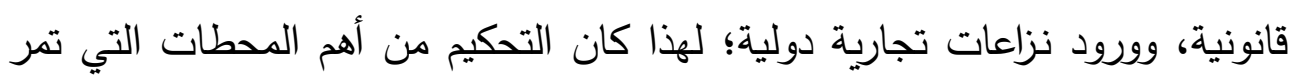
عليها عقود نقل التكنولوجيا، رغم الصعوبات العملية في تطبيق مبدأ حرية الإرادة والقانون الواجب التطبيق، لاسيما في حالة عدم وجود تشريع خاص بنقل التكنولوجيا،

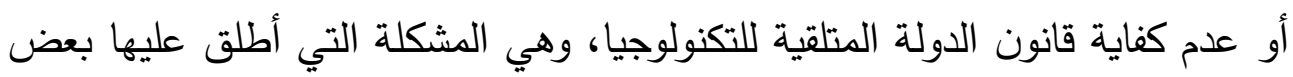
الفقهاء "مشكلة الفراغ في القانون الواجب التطبيق"(')؛ الثيء الذي يجعل حرية الأطراف مقيدة في اختيار هذا الأخير . كما أن عقد نقل التكنولوجيا يخضع لقانون الدولة المتلقية لهذا النقل إذا كان الأمر له علاقة بسيادتها، أما في الأمور المتعلقة بنقل التكنولوجيا واستثمارها في المصالح الخاصة فللأطراف حرية اللجوء إلى المبادئ القانونية الدولية باعتبارها من المبادئ التي تحاول تسهيل النقل التكنولوجي، واختيار القانون الواجب التطبيق.

(1) يوسف عبد الهادي الإكيابي، النظام القانوني لعقود نقل التكنولوجيا، م.س، ص r ب70. 


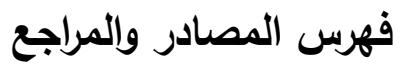

$$
\text { أولا: الكتب: - أب }
$$

1-آمال زيدان عبد اللاه، الحماية القانونية للأسرار التجارية في عقود نقل

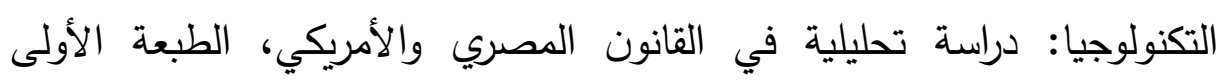

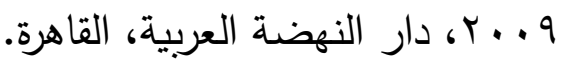

r- أحمد عبد الكريم سلامة، شروط الثبات التشريعي في عقود الاستثار والتجارة

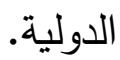

r- أشرف عبد العليم الرفاعي، القانون الواجب التطبيق على موضوع التحكيم

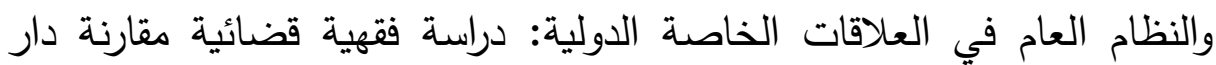

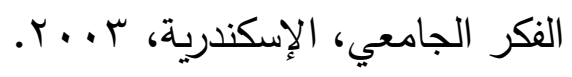

ع - بثار الأسعد، عقود الدولة في القانون الدولي.

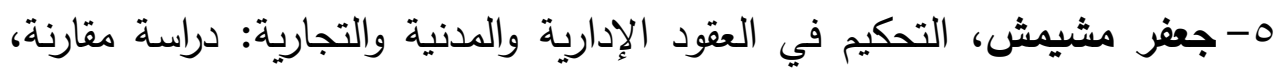
الطبعة الأولى، 9 . . †، منشورات زين الحقوقية، بيروت، لبنان.

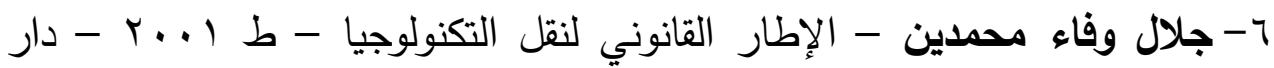

$$
\text { الجامعة الجديدة للنشر - الإسكندرية. }
$$

V- حفيظة العيد الداد، العقود المبرمة بين الدول والأشخاص الأجنبية: تحديد ماهيتها والنظام القانوني الحاكم لها، منشورات الحلبي الحقوقية، بيروت، لبنان. 1- خالا محمد القاضي، موسوعة التحكيم التجاري الدولي في منازعات المشروعات

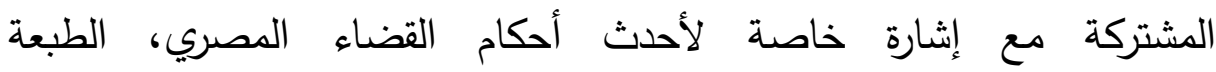

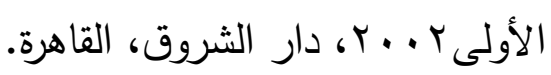

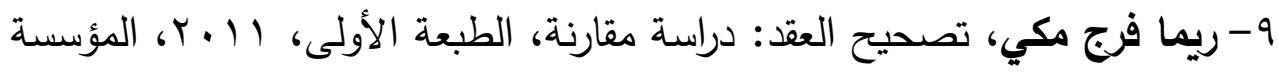

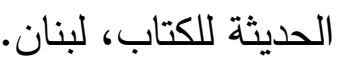

• 1- صلاح الدين جمال الدين، عقود نقل التكنولوجيا: تنازع القوانين وتسوية

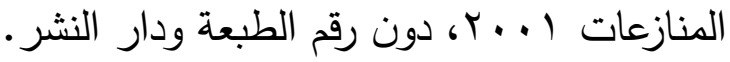


|| - غسان عبيد محمد المعموري، شرط إثبات التشريعي محوره في التحكيم في

عقود البترول.

r ا - فه بجاد الملاخ - تسوية منازعات عقد نقل التكنولوجيا - ط 9 ـ. . - دار

$$
\text { النهضة العربية - القاهرة. }
$$

rا - محمد خيري سمير الأمين - الوكالة التجارية وعقود نقل التكنولوجيا طبعة

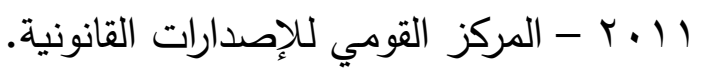

ع ا - محمود الكيلاني، الموسوعة التجارية المصرفية.

10- مراد محمود المواجدة - المسئولية المدنية في عقود نقل التكنولوجيا - ط ط

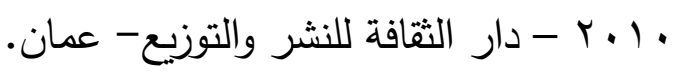

7 ا - ممدوح ومنير محمد الجنبيهي - العقود التجارية - طبعة ... . ب، دار الفكر

$$
\text { الجامعي، الإسكندرية. }
$$

IV - هثام صادق، القانون الواجب التطبيق على عقود التجارة الدولية: دراسة تحليلية ومقارنة للاتجاهات الحديثة في التشريعات الداخلية، والاتفاقيات الدولية وأحكام القضاء والمحكمين، وتوصيات مجمع القانون الدولي، مع إشارة خاصة لموقف المشرع المصري سواء في التقنين المدني وفي قانون التحكيم الجديد رقم

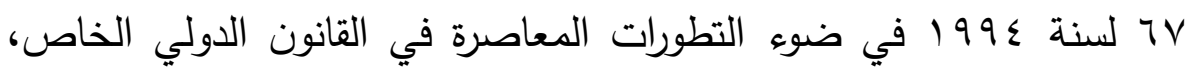
منشأة المعارف الإسكندرية 1990 . 1 ا - يوسف عبد الهادي خليل الإكيابي - النظام القانوني لعقود نقل التكنولوجيا في مجال القانون الدولي الخاص.

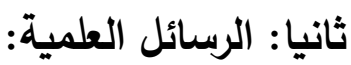
1- أحمد أدريوش، أصول قانون الالتزامات والعقود، بحث في الأصول الفقهية، دكتوراه الدولة في الحقوق، جامعة محمد الخامس، الرباط، السنة الجامعية 


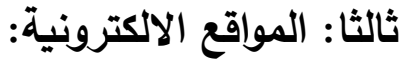

1- http://jilrc-magazines.com

$$
\text { رابعا: المجلات العلمية: - المبلة }
$$

1- المجلة المصرية للقانون الدولي، المجلد الخمسون، السنة الخمسون، ؟ 99 1.

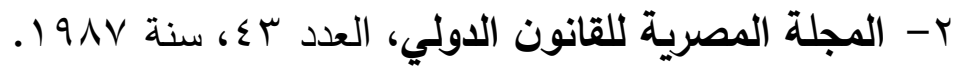

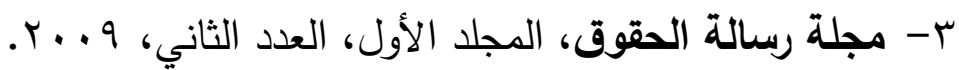

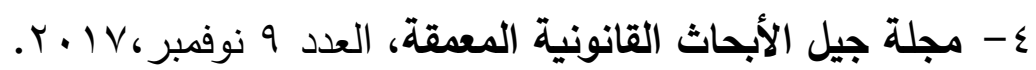

